\title{
Use of damage in fire investigation: a review of fire patterns analysis, research and future direction
}

\author{
Gregory E Gorbett ${ }^{1,2^{*}}$, Brian J Meacham ${ }^{1}$, Christopher B Wood ${ }^{1,3}$ and Nicholas A Dembsey ${ }^{1}$
}

\begin{abstract}
Fire investigators have historically relied upon damage as a means to conclude where a fire originated. This review evaluates the historical and current literature on the topic, with a specific emphasis towards the research conducted over the past 80 years related to fire patterns. The concept of fire patterns for this review has been broken into four components that better assist in evaluating their effectiveness in determining an area of origin. The first component evaluated is the ability to assess the varying degree of fire damage along the surfaces of the compartment and contents. Next, the ability to identify clusters of damage was evaluated. Interpretation of the causal factors for the generation of the fire patterns was next appraised. Finally, the availability of processes using fire patterns in determining an area of origin was assessed. This deconstruction of the problem provides a gap analysis of the current processes and identifies areas where future work is needed. A seven step reasoning process for evaluating damage for determining the area of origin, along with a new definition for the term fire pattern is proposed.
\end{abstract}

Keywords: Forensic science; Fire investigation; Fire patterns; Fire damage; Fire effects

\section{Introduction}

Forensic science is defined as the application of a broad spectrum of sciences to answer questions of interest to the legal system, including both criminal and civil actions (Houck and Siegel 2006). The job of a forensic scientist is to provide scientific evidence, notably the analysis of scientific or engineering data, to the justice system in order to reduce uncertainty (Taroni et al. 2010). Scientific evidence is always incomplete to some degree, which means there is a measure of uncertainty associated within each analysis. Consequently, the forensic scientist must interpret and present the significance of the evidence to the court of law (Taroni et al. 2006).

The investigation of fires is one of the more complicated forensic sciences due to the continuously altered or destroyed evidence by the fire itself. Fire is a highly three-dimensional, time-variant process with time-variant

\footnotetext{
* Correspondence: greg.gorbett@eku.edu

'Department of Fire Protection Engineering, Worcester Polytechnic Institute, 100 Institute Road, Worcester, MA 01609, USA

${ }^{2}$ Department of Fire Protection and Paramedicine Sciences, Fire, Arson and Explosion Investigation Program, Eastern Kentucky University, 521 Lancaster Avenue, Richmond, KY 40475, USA

Full list of author information is available at the end of the article
}

boundary conditions. The other difficulty for forensic scientists investigating fires is that the observations of damage after the fire may often times be independent of the path taken by the fire making it difficult to identify where the fire started. Thus, a fire investigator must have a solid grasp of the physics and variables that influence a fire's development, as well as how these variables may or may not have influenced the damage outcome.

Fire investigation (origin and cause determination) is an integral part of the total fire safety model, including fire prevention and protection for a community. Fire investigation plays a critical role in identifying potentially faulty or improperly designed and installed products that may have played a role in the fire and in identifying persons that deliberately started a fire with malicious intent.

The scene investigator's most important hypothesis is the correct identification of the origin of the fire (NFPA 2014). The origin determination is necessary to make an accurate cause assessment. Proper fire investigation should determine the fire cause, the cause of the resulting property damage and most importantly, the cause of bodily injury or loss of life to civilians and firefighters.

\section{实}


Since the beginning of organized fire investigation in the late 1940's, fire investigators have relied on fire patterns as their basis for determining the fire origin (Rethoret 1945). Fire patterns are defined as the "visible or measurable physical changes, or identifiable shapes, formed by a fire effect or group of fire effects" (NFPA 2014). Absent the testimony of reliable eyewitnesses to or recording of the fire's inception, the investigator is required to determine the origin by observation and expert interpretation of the physical evidence (e.g. fire patterns) in an attempt to reconstruct the fire's development. As such, fire origin determination is largely a matter of fire pattern recognition and interpretation (NFPA 2014).

Presently, much of this interpretation is implicit and subject to investigator bias, with assignment of interpretation to patterns being largely dependent on the investigator's knowledge, experience, education, training and skill, without the benefit of a structured framework to help guide the investigator through the process. This is of particular concern with respect to the importance of being able to identify and properly weigh potentially subtle differences from one fire scene to the next, some of which could have significant bearing on the development of the fire and the interpretation of the evidence.

However, not all fire investigators have the same level of education and training, or appreciation for the interaction of the fire in its environment. Historically, fire investigators have been individuals without any formal education or training in scientific methodology. A survey was conducted by the National Center for Forensic Sciences (NCFS) in 2000 where 422 fire investigators revealed that only $33 \%$ held a college degree, of which only $10 \%$ were related to science or engineering (Minnich 2000). This survey also related that the average fire investigator has only received $60 \mathrm{~h}$ of training, indicating a one-to-two week course. A survey conducted in 2012 reflected similar findings to that of the NCFS survey where 586 fire investigators revealed that $50 \%$ had a bachelor's degree or higher, of which only $18 \%$ were related to science or engineering (Tinsley and Gorbett 2013). This suggests that many investigators have received the majority of their training through informal on-the-job training. More experienced fire investigators would mentor less experienced fire investigators, unfortunately in some cases, passing on what has since become realized as a collection of myths (NFPA 2014).

The failure in knowledge transfer is most likely because experienced investigators, particularly those who obtained their basic training before 1992, were trained with misinformation and misconceptions (Lentini 2012). A number of those investigators have taken very little additional training since their basic training and, of those, some do not recognize how flawed their early training was or the impact of how the lack of training regarding current techniques influences their conclusions. The most recent example of this failure resulted in the execution of Cameron Todd Willingham by the State of Texas on the basis of an investigation that relied on "poor understandings of fire science and investigators that failed to acknowledge or apply the contemporaneous understanding of the limitations of fire indicators" (Beyler 2009).

The legal and science professions are currently scrutinizing forensic science, which is forcing the nation to question the discipline's scientific foundation (NIJ 2009). Recently, the National Academy of Sciences released a cautionary report regarding analysis that requires expert interpretation of observations (NIJ 2009). In the report, the authors outlined the need to improve the scientific foundations of the forensic disciplines, particularly those that are dependent on qualitative analyses and expert interpretation of observed patterns, including fire investigations (NIJ 2009). One recommendation called for those forensic science disciplines that rely on human interpretation to "adopt procedures and performance standards that guard against bias and error" (NIJ 2009).

The present paper establishes a review of the work done over the past 80 years, which addresses the current situation of the profession in light of this recommendation by the National Academy of Sciences.

\section{Background}

The terminology associated with fire patterns and their use in origin determination has evolved over the past 80 years, so the first task was to identify any separations within the work to better organize the presentation of the literature. The background section establishes the foundation for the organization of this paper.

The earliest texts on fire investigation expressed the importance of using damage and fire patterns in determining the area of origin (Rethoret 1945; Straeter and Crawford 1955; Kennedy 1959; Kirk 1969). Generally, these texts encouraged investigators to visibly identify which side of a content item, wall, or structural member may have been more affected by heat. The varying damage was given many terms by fire investigators and is reflected within the literature, including: fire patterns, burn patterns, indicators, burn indicators, fire fingerprints, fire transfer patterns and a variety of geometric shapes. Regardless of the terminology used, these fire patterns were used as a means to trace the fire back to the location where it started, the area of origin. Most of the earlier literature supported the idea that specific patterns were indicative of causal links or to the speed of the fire, which was mostly linked to incendiary fires (e.g. pour patterns). Most of these earlier texts, however, do not offer a process on how to use the data, other than vague descriptions on visibly identifying greater areas of 
damage and tracing fire patterns. Around the late 1970's there was a movement within the profession to describe fire patterns by descriptions of their geometric shapes (e.g. V-pattern, U-pattern, hourglass-pattern). The characteristics associated with the geometric shapes were in some cases linked to the speed of the fire, such as the angle of the $\mathrm{V}$ could be interpreted as the fire being fast or slow. These geometric shapes are still currently used within the profession, however, many of the myths associated with their interpretations have fallen into disrepute.

Given the history of using fire patterns within the fire investigation profession, it was reasonable that they would also be included in the first edition (1992), and all subsequent editions of NFPA 921 Guide for Fire and Explosion Investigations. NFPA 921 is recognized as establishing the standard of care for the fire investigation profession and is the only consensus document that exists for fire investigators. The importance of fire patterns is clearly reiterated in Section 6.1.1 by stating "the major objective of any fire scene examination is to collect data as required by the scientific method. Such data include the patterns produced by the fire" (NFPA 2014). The chapter on fire patterns underwent reorganization between the 2004-2008 editions to divide fire effects and fire patterns. This was the first time that a distinction was drawn between damage caused by the fire (fire effects) and clusters of fire effects that may have characteristics that assist the fire investigator (fire patterns). Fire effects are the physical or chemical changes that occur to different materials when exposed to the byproducts of combustion (e.g. melting of plastics, oxidation of metals). Fire patterns are identified as the collection of these effects and geometric shapes that these effects produced.

NFPA 921 further lists that fire patterns can be classified by their generation or causal relationship to the fire dynamics by providing the following classes: plumegenerated patterns, ventilation-generated patterns, hot gas layer-generated patterns, full-room involvementgenerated patterns and suppression-generated patterns (NFPA 2014).

Assessing the historical and current semantics of the fire investigation literature, the use of fire patterns to determine an area of origin, for purposes of the current paper, can be grouped into four areas of literature that need to be reviewed, including:

(1) Assessing the varying degrees of fire damage (DOFD) along the surfaces of the compartment and contents (i.e. fire effects);

(2)Identifying clusters and trends of damage (i.e. fire patterns);

(3) Interpreting the causal factors for the generation of the fire patterns; and,

(4)Identifying processes of using fire patterns in determining an area of origin.

\section{Objective of the paper}

The objective of this paper is to review the work that has been done to observe or measure varying damage along compartment and content surfaces, identify fire patterns, identify causal factors for the fire patterns and apply this information within a process to identify an area of origin, as well as identify gaps and propose new approaches. A literature review was performed in order to achieve the objectives of this study. The literature was received from different databases, primarily ScienceDirect (2012), International Symposium on Fire Investigations conference proceedings, Fire and Arson Investigator-Journal for the International Association of Arson Investigators and fire investigation textbooks. The following keywords were used for the literature review, including: fire patterns, fire effects, fire investigation, arson investigation, burn patterns and burn indicators.

The literature review is limited to structure fire studies. The majority of the experimental work has been conducted in small, residential-sized compartments with one or two ventilation openings. The majority of this review is of North American work. Additional file 1 outlining the variables for all experimental tests reviewed has been developed and also provided.

\section{Literature review}

There are four logical components to the literature review presented:

- The first part of the review describes the work completed for establishing a degree of fire damage assessment for commonly encountered materials in structure fires.

- The second part isolates the work conducted on identifying fire patterns and the characteristics associated with these trends within the damage.

- The third part of the review focuses on the possible causal factors influencing the location and magnitude of damage.

- The fourth part of the review focuses on the practice of using damage in fire investigation to assist in determining the area of fire origin.

\section{Literature on establishing a degree of fire damage assessment}

When a fire develops in an enclosure, the products of combustion (e.g. heat, soot) begin to influence the materials within the compartment. Thus, the lining materials for the walls, ceiling and floor, as well as the various materials that make up the contents within the compartment, are damaged by this exposure to the products of combustion. The fire investigation community terms the resulting damage as fire effects, which are defined as "the 
observable or measurable changes in or on a material as a result of exposure to the fire" (NFPA 2014).

The degree to which materials are influenced by the developing fire will be a function of the material characteristics, temperature of the products of combustion and the duration of exposure (NFPA 2014). There are numerous factors that may influence how a material is affected by heat and exposure to incomplete combustion products (e.g. smoke, aerosols). The loss of mass from a material is typically dependent on the material and the exposure to heating. A short list of material properties that may also influence the effects of a material exposed to a fire environment includes: moisture content, thermal conductivity, density, specific heat, critical heat flux, ignition and flame spread propensity and heat of gasification/ vaporization (NFPA 2014).

The damage data used by fire investigators in origin determination starts with the ability of the investigator to observe varying damage along surfaces of contents, walls, ceiling, floor and structural members. The fire investigator's observations are simply assessing the varying DOFD. Identification of varying DOFD throughout the compartment serves as the basis for interpretation by the investigator. Fire investigation textbooks, guides and studies describe the use of lines or areas of demarcation in assessing damage. The areas of damage and boundaries of those areas are often referred to as areas and lines of demarcation. Areas of demarcation are locations along a surface that exhibit similar damage characteristics (e.g. magnitude of damage, type of fire effect, color, texture) and are in close proximity to each other. Lines of demarcation are "the borders defining the differences in certain heat and smoke effects of the fire on various materials. They appear between the affected area and adjacent, less-affected areas" (NFPA 2014). Fire investigators are instructed to visually and measurably identify these areas and lines of demarcation.

Ideally, the investigator would be able to look at a material's surface and distinguish the varying DOFD across its surface and this examination would be consistent with the findings of other qualified investigators. However, fire investigators currently use their visual interpretation to give vague descriptions on the varying degrees of damage when reporting their findings. Many fire investigation reports, textbooks and standards inconsistently report degrees of damage, using a wide range of undefined modifiers, such as greater, lesser, heavy, light, minor, moderate, major, severe and large, in an attempt to distinguish between levels of damage that they observe and are trying to convey (DeHaan and Icove 2011; Lentini 2012; Madrzykowski and Fleischmann 2012; NFPA 2014; Shanley et al. 1997).

There are a total of 17 fire effects listed in NFPA (2014) that serve as the base list of observations for fire investigators (Table 1). There are hundreds of materials
Table 1 Base list of fire effects and observations identified in NFPA (2014)

\begin{tabular}{|c|c|c|}
\hline \multirow[t]{2}{*}{ Fire effect } & \multicolumn{2}{|c|}{ Observation(s) } \\
\hline & Visible & Measurable \\
\hline Temperature estimation & $x$ & \\
\hline Mass loss & $x$ & $x$ \\
\hline Char & $x$ & $x$ \\
\hline Spalling & $x$ & \\
\hline Color changes & $x$ & \\
\hline Melting of materials & $x$ & \\
\hline Thermal expansion and deformation & $x$ & $x$ \\
\hline Oxidation & $x$ & \\
\hline Deposition & $x$ & \\
\hline Clean burn & $x$ & \\
\hline Calcination & $x$ & $x$ \\
\hline Window glass & $x$ & \\
\hline Furniture springs & $x$ & \\
\hline Victim injuries & $x$ & \\
\hline Light bulbs & $x$ & \\
\hline Rainbow effect & $x$ & \\
\hline Enhanced soot deposition-smoke alarms & $x$ & \\
\hline
\end{tabular}

that can be found in residential occupancies, as such there are thousands of studies that would need to be reviewed and summarized here to identify the characteristics of the material properties and the impact that heat has on each material. The focus of this literature review is to identify the work that has been done specifically for forensic applications that have been conducted for identifying ways to observe and characterize varying degrees of fire damage through measurable or visible means. Wood and gypsum wallboard (drywall) were the only materials that had sufficient literature to review in this context.

\section{Wood (Char)}

Wood has been and remains a common material used for construction of structures and contents. Therefore, fire investigators within most fire scenes typically find charred material. As such, fire investigators have written about the use of visible and measurable observations related to varying damage to wood for as long as fire investigation has been in existence (Rethoret 1945). However, the visible and measurable observations used in identifying the varying degree of charring have had many misconceptions.

The early texts on fire investigations promoted the use of identifying the varying degree of charring throughout the compartment to assist with origin determination. Rethoret (1945) describes that the fire investigator should "study closely the depth of carbonization at various places, 
as this will bring the investigator in getting back to the point of origin". Straeter and Crawford (1955) text identified that "the point of deepest char in the wood is likely to be the point of origin of the fire". Kennedy (1959) relates that "wooden joists or studding are exposed to burning... the sides exposed to the direction from which the fire is coming will be more severely burned and charred". Prominent forensic scientist, Paul Kirk (1969), wrote in support of using depth of char for fire investigation in the following, "variations in depth of the char will inevitably be noted...and that this feature of the fire is of primary importance". None of these texts, however, provided a methodology to the reader on how to go about identifying what constitutes greater and lesser visible or measurable char damage.

Measurable damage The use of depth of char and relating this depth to duration of burning has fluctuated as to its usefulness in fire investigations since the mid1950's. Kirk's (1969) text was the first reference that indicated investigators could use this data for more than just direction of damage when he explained "investigators make measurements with the idea of determining the length of time the fire burned at this point". However, Kirk cautioned that investigators should not place "more than casual emphasis" on placing a direct relation between char depth and time of burning due to the number of variables that could influence the findings and the lack of reliably controlled test data available (Kirk 1969). Despite this warning, several textbooks and journal articles discuss that an investigator can prescribe a 45 min duration of burning for every 1-inch of char depth (Stickney 1984; Kennedy and Kennedy 1985; Swab 1985). However, others argued that many variables such as the type of wood, variations in burning within the compartment, firefighting operations and orientation of the wood influenced the rate of charring and suggested that investigators only use the locations of greater depths as relative longer exposures to heating that should not necessarily be tied to a duration of burning (Kirk 1969; DeHaan 1983; Ettling, 1990).

This "rule of thumb" of burning duration had been the source for some misconceptions related to determining if a fire was incendiary and fell into disrepute around the mid-1990's. In the first edition of NFPA (1992) the investigator was cautioned, "that no specific time of burning can be determined based solely upon depth of char". Schroeder later confirmed this assessment by performing a variety of constant heat flux and duration exposure tests on an assortment of wood samples in an attempt to determine if wood could be reliably evaluated by the fire investigator for intensity and duration (Schroeder 1999). Schroeder's results varied widely as to depths of char in relation to the duration and intensity of exposed heat flux, which led him to conclude that wood was not a good indicator for predicting intensity of duration of exposures.

Babrauskas (2005) summarized the research of charring wood and the research behind the use of depth of charring for fire investigators and found that "under conditions of severe, post-flashover room fires, heavytimber or similar members that have no gaps or joints will char at similar rates to those found in fire-resistance furnace tests - roughly $0.5-0.8 \mathrm{~mm} / \mathrm{min}$ "... and that "this can be a useful tool in estimating a minimum value for post-flashover burning of the room fire". However, he found "that much higher charring rates apply to floors and to any other wood members where charring is affected by the presence of gaps or joints".

Visible damage In the early days of fire investigations a common rule among fire investigators was that the visible observation of large shiny blisters of wood char indicated fast fires and that small dull blisters indicated a slower fire, which assisted investigators to conclude that a fire was incendiary or not (Boudreau et al. 1977; Brannigan et al. 1980; Keith and Smith 1984; King 1985; Ettling 1990). The Law Enforcement Assistance Administration (LEAA) documented many of the myths about using the visible appearance of damage to identify arson with the visible appearance of char being one of the predominant misconceptions (Boudreau et al. 1977). Arson investigators were surveyed about how they investigate fires and cited interpretation of "alligatoring" as one of the most common methods of establishing arson. For example, if an investigator observed charred wood with "large, rolling blisters" giving it the appearance of alligator skin, then the fire investigator was to interpret this as a "rapid" fire which was often used then used in concluding that the fire was incendiary in nature. This misconception was so ingrained in the profession that it was repeated as fact in the Fire Investigation Handbook published by the National Bureau of Standards (Brannigan et al. 1980).

The first reference that can be identified related to rejecting this misconception was a discussion by DeHaan (1983). Additional researchers and texts disavowed the use of this visible observation and its connection to the speed of fire (Cooke and Ide 1985; Ettling 1990; NFPA 1992).

Only one article was identified related to the use of visible char appearance in identifying varying DOFD where quantitative measures were attempted (Keith and Smith 1984). This article reiterated the same alligatoring misconception as promulgated at the time, but despite this connection the goal of the article was to establish a method of defining varying DOFD for the visible observation of char (Keith and Smith 1984). In this work, the authors outlined a system that described char as being 
on a range from 'Number 0 Char' up to 'Number 10 Char', with number 10 char as representing the greatest level of damage. The level of damage was varied based on the visible appearance of the number of cracks within set distances and the widths of those cracks. For example, an investigator would assign a number 5 char level to a piece of wood that had "the number of cracks occurring up to 2 per centimeter with widths approximately the thickness of a five-cent piece" (Keith and Smith 1984). The DOFD as outlined in this article never received any traction within the community and has never been picked up in any other literature (Figs. 1 and 2).

\section{Gypsum Wallboard / Drywall (Calcination)}

Gypsum wallboard is one of the more common lining materials for walls and ceilings used for construction of residential and commercial facilities. Gypsum wallboard is a common structural lining material consisting of a core of gypsum (calcium sulfate dihydrate) sandwiched between two paper facers (McGraw and Mowrer 1999).

There are several effects that may occur to gypsum wallboard when exposed to heat and fire conditions, including: color changes, soot deposition, charred paper, paper consumed and clean burn (Fig. 4). Determining which effect or effects reflect varying degrees of damage is the key to successfully assessing damage. Two methods are used to visibly interpret damage on gypsum wallboard (1) cross-sections of the wall can be evaluated for visibly identifiable changes to the gypsum wallboard through depth and (2) the surface effects can be evaluated for visibly identifiable varying DOFD.

Much of the earlier published research was focused on examining cross-sections of the wallboard, visibly determining the depth of calcination based on different bands of color within the cross-section (Posey and Posey 1983). The Posey study reported that an investigator could visibly identify subtle color changes in individually cut cross-sections of the wallboard and prescribe the DOFD

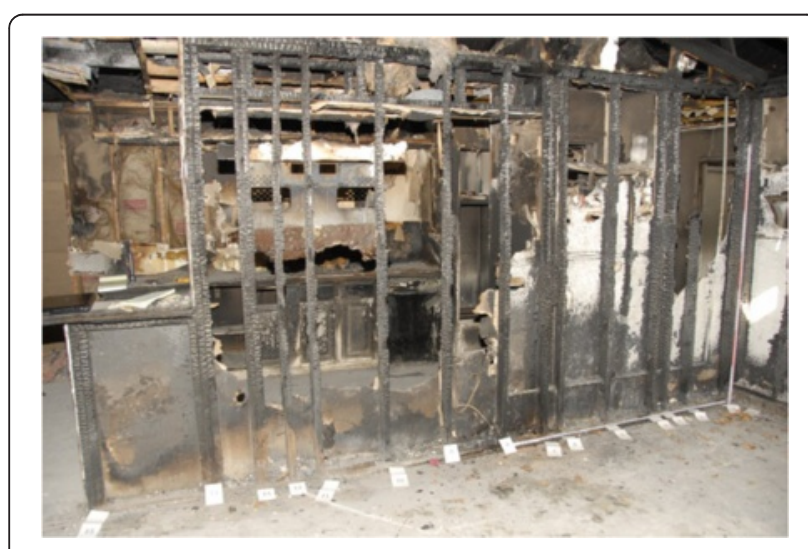

Fig. 1 Wood stud wall with varying DOFD char damage

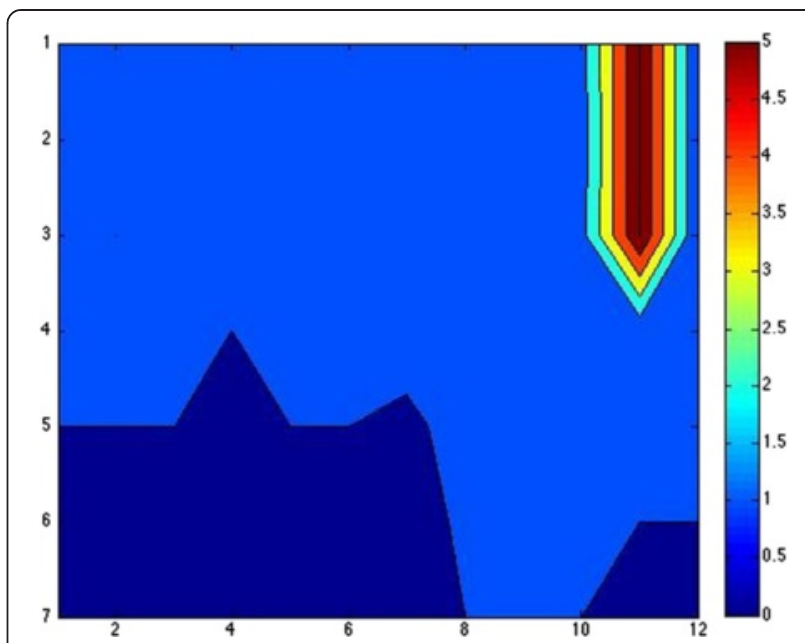

Fig. 2 Depth of char contour plot of wood stud wall depicted in Fig. 1

associated with the color changes. Several researchers supported this analysis but questioned the practical application of such a method (Schroeder 1999; Kennedy et al. 2003). Other researchers have shown that the crosssectioning method is misleading, as well as having significant procedural drawbacks (Mann and Putaansuu 2010; Mealy and Gottuk 2012). Most recent studies consider taking the actual depth of calcination by using an instrument and probing it into the wall a more effective method (Mann and Putaansuu, 2010; Mealy and Gottuk, 2012; Kennedy et al. 2003). Therefore, the visual identification of color changes through the cross-sectioning of wallboard will not be further addressed.

Measurable damage The first reference that fire investigators were able to use depth of calcination for origin determination can be found in 1955, where the authors of this text relate depth of char methods to that which can also be done to "spoiled plaster (drywall) or concrete may indicate the point of origin by a similar means of determining greatest damage" (Straeter and Crawford 1955). The Schroeder study (1999), however, was the first to quantify the depth of calcination and its relationship within fire investigations. In this study, experimental samples of gypsum wallboard were exposed to various heat fluxes at varying durations using the ASTM E1354, Cone Calorimeter radiant heater. Schroeder was able to illustrate that a crystalline change would occur within the gypsum wallboard when heated by using an x-ray diffraction technique. His findings indicate that gypsum wallboard was the only material that could be reliably used for predicting intensity and duration purposes. However, Schroeder's study did not produce an effective means for implementing this method into a scene inspection. 
Ngu (2004) performed similar experimental work as Schroeder (1999). In the Ngu study, a series of power law correlation plots were developed between the calcination of gypsum wallboard and the total heat exposure for various types and thicknesses of the material (2004). From this work, Ngu developed a tool based on a constant spring force and a force probe. Ngu performed simple bench top tests to evaluate this tool's ability to reliably obtain depth measurements. Ngu did not test this methodology for application toward full-scale fires for investigation purposes.

Mealy et al. (2013) designed a tool based on the previous work of $\mathrm{Ngu}$ (2004), which used a force gauge with an attached hex key probe ( $2 \mathrm{~mm}$ diameter). The Mealy, Wolfe and Gottuk study used the Ngu force gauge to ensure that the user performed their measurements with similar force (Mealy et al. 2013). They confirmed that $6.6 \mathrm{lbf}$ ( $3 \mathrm{kgf}$ ) of force was best at matching the Fourier Transform Infrared spectroscopy (FTIR) chemical analysis of dehydration found in the Mann and Putaansuu study (2010). The Mealy study (2013) indicated that a variance on the depth measurements, regardless of the user, was negligible ( 10\% variance) and that the method worked at reliably indicating fire travel, especially when no visible observations could be made. The Mealy, et al. study (2013) also demonstrated that when visual damage to the wall surfaces were unable to provide enough data for analysis that contour plots of the depth measurements "provided valuable insight into the areas within the enclosure that were subjected to the most severe thermal damage, the areas in which the initiating (primary first fuel) fire occurred". This quote, however, is not to generalize that the area of origin is to be equated with the area of greatest thermal damage outside of this specific test series.

Although these studies demonstrated that depth of calcination surveys assisted in the area of origin determination, neither developed a process to quickly process a fire scene. The prescribed process by Mealy (2013) was time consuming due to the requirement on the user to be extremely careful in watching the gauge and then marking the probe with a piece of tape to document the depth, thus introducing potential error.

Barnott et al. (2013) developed a constant force depth of calcination tool to eliminate inconsistencies in depth of calcination measurements to provide a more practical application of the tool based on the $\mathrm{Ngu}$ (2004) and Mealy (2013) studies. The tool used constant force springs to ensure an even, consistent pressure is applied at all times regardless of the user. The tool is built around a digital indicator gauge commonly used in machining. The gauge is capable of reading measurements to 0.0005 " (0.01 mm).

The constant force is applied to the tool by two $3.3 \mathrm{lb}$ constant force springs. The use of 2 springs running parallel to each other allows for equal pressure on each side of the tool (Fig. 3). The measuring pin is constructed of a $2 \mathrm{~mm}$ cobalt drill bit. The pin size was based on the Mealy (2013) research, which resulted in a pressure of $1175 \mathrm{psi}\left(0.86 \mathrm{~kg} / \mathrm{mm}^{2}\right)$. Resistance in the tool system is minimized through the use of UHMW-PE TIVAR plastic on all sliding surfaces, eliminating metal on metal contact. This includes the spring housing and rear slider block. This study also developed a simplified grid system out of tent pole stakes to decrease scene processing time.

Visible damage Most investigators in the field do not cut out pieces of the wallboard to visibly identify damage, nor do they perform depth surveys using a depth tool. Typically, investigators look at the face of the wallboard and make a visible determination of the DOFD. The visible appearance of wallboard has been utilized in all fire pattern studies available, even though only a few studies exist that focus on the baseline characteristics of the varying degree of heating and resulting DOFD (Madrzykowski and Fleischmann 2012; Hicks et al. 2008; Mann and Putaansuu 2009). Therefore, no systematic scale for the degree of damage had been proposed or adopted. NFPA 921 (NFPA 2014) provides some generic guidance regarding the changes in visible appearance to gypsum wallboard in response to heating, but no formal scale had been proposed.

Hicks et al. (2006; 2008) conducted a fire pattern reproducibility study using single fuel items. Forty-eight tests were conducted with a standardized ANSI/UL wood crib and ten additional tests were conducted with commercially available polyurethane foam recliners. The fuels were burned against a gypsum wallboard lining material within a compartment lined with gypsum wallboard. Twelve thermocouples were mounted in a grid array above the fuel item to capture temperatures for the duration of the tests. These two studies demonstrated a relatively predictable response of visible damage to the gypsum wallboard consistent with the varying DOFD identified in NFPA 921 (Figs. 4 and 5).

Madrzykowski and Fleischmann (2012) performed a study of the response of gypsum wallboard and the reproducibility of the damage pattern created when exposed to known heat release rate (HRR) fires with varying types of fuel sources and wall construction. The fuels used for their experiments included a natural gas burner, gasoline pool fire and polyurethane foam. The wall construction was varied between a single sheet of gypsum wallboard with wood framing, a gypsum wallboard front and back with wood framing and gypsum wallboard front and back with fiberglass batt insulation in the voids of the wood framing. The gypsum wallboard was covered with a primer and cover coats of latex paint. 


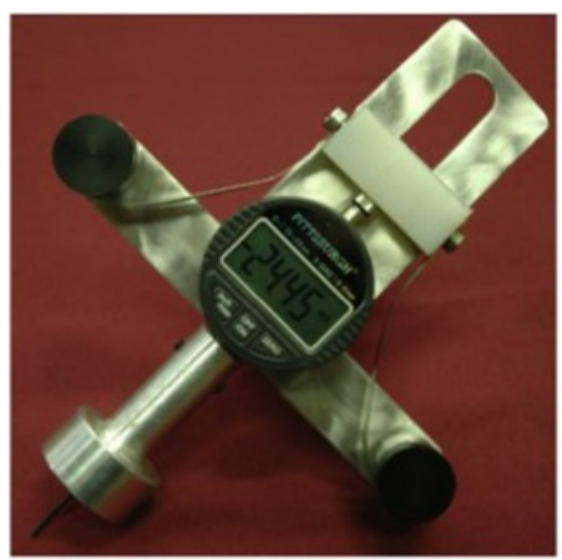

a

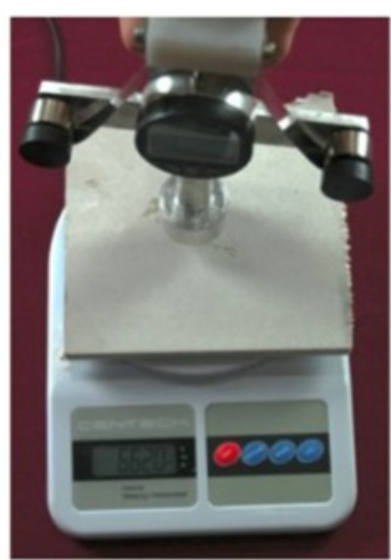

b

Fig. 3 a Depth of Calcination Tool Developed for Constant Pressure Measurement, (b) 6.6lbf (3 kgf) Confirmation (Barnott et al. 2013)

This study focused on the effects where the paper had been burned away (consumed) and where the paper had been peeled up (penetration). To accomplish this, the researchers evaluated the variability of the flame height in comparison to the height and area of damage. As expected, the results indicated that the patterns generated by the polyurethane foam fire had greater uncertainty than the natural gas and gasoline pool fires. The wall construction had no significant impact on the damage.

Mann and Putaansuu (2010) exposed samples of gypsum wallboard to three levels of heat flux for three different durations and noted visible changes, as well as depth of calcination changes with a variety of probing instruments. Their study reported that the fire damage to the surface and internal cross section of the wallboard occurs progressively in the following manner:

1. Soot coating of undamaged facing paper;

2. Discoloration/degradation of facing paper;

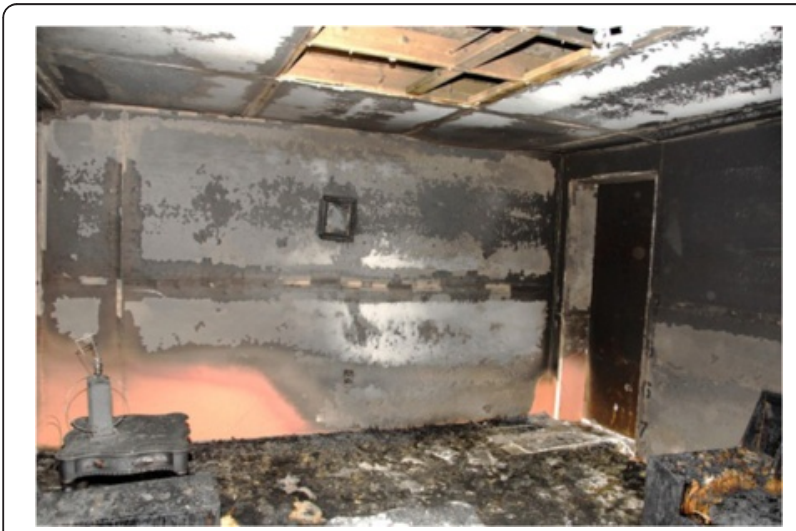

Fig. 4 Varying degree of fire damage to gypsum wallboard-visible damage results
3. Facing paper burns away;

4. Partial dehydration and discoloration/soot staining of surface layer of gypsum;

5. Formation of anhydrous and hemihydrate layers with layers progressing through the cross section;

6. Complete conversion of dihydrate to anhydrous and hemihydrate;

7. Anhydrous extends through the entire cross section;

8. Wallboard becomes catastrophically heat damaged and lacks structural integrity.

Mealy et al. (2013) also discuss findings related to the visual identification of surface damage progression to gypsum wallboard based on imposed heat fluxes. They further confirmed the NFPA 921's and Mann and Putaansuu's progressive visible damage to the surface of the gypsum wallboard.

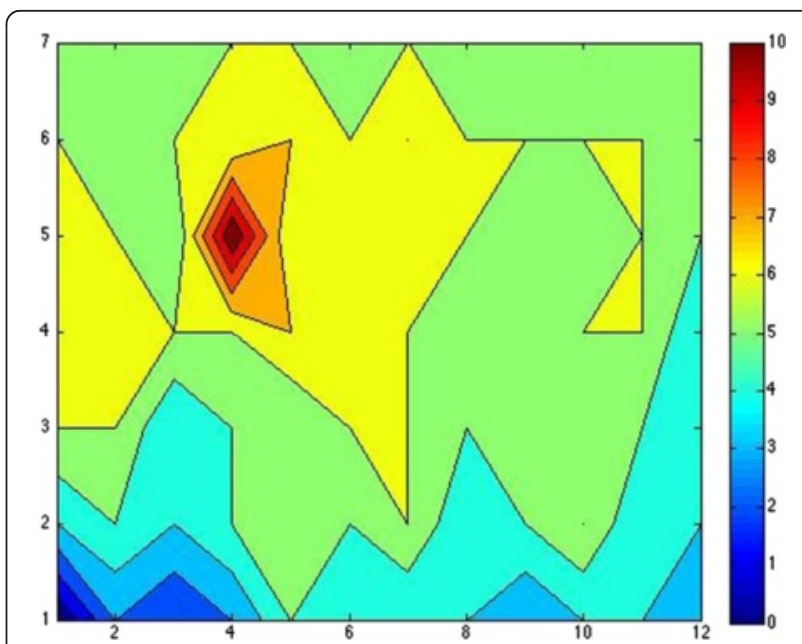

Fig. 5 Varying degree of fire damage to gypsum wallboard-contour plot of the depth of calcination results of Fig. 4 
Riahi studied the soot deposition characteristics of three different fuels in bench-scale experiments and then against a gypsum wallboard lined wall (Riahi and Beyler 2011; Riahi 2012; Riahi et al. 2013). An optical measurement method was developed to arrive at optical properties of smoke deposited out of a smoke layer onto glass filters. From this work, the researchers used gravimetric measurements of these filters to demonstrate and validate an analytical model for smoke deposition based on thermophoresis. Consequently, a new optical measurement method was developed to use with digital photographs and digital image analysis. The researchers used ImageJ software and a Kodak gray scale and found good agreement between the optical measurement methods and smoke pattern images developed along wall surfaces. Their study showed that "the smoke pattern was determined for the wall tests and showed a difference between test conditions and very good agreement for the method for all test conditions" (Riahi 2012). They also stated that "based on the clean zone area, the flame height and the fire size can be calculated" (Riahi 2012). Finally, the study was conducted with a variety of digital cameras and they found that the optical properties were not dependent on the camera used.

The varying DOFD discussed in NFPA 921 is consistent with the findings from the existing studies (Schroeder 1999; Hicks et al. 2006; Hicks et al. 2008; Mann and Putaansuu 2010; Madrzykowski and Fleischmann 2012; Mealy et al. 2013). A DOFD scale for gypsum wallboard was developed and tested based on the findings from these studies (Gorbett et al. 2014). In this study, a DOFD scale was developed as a ranking system to reflect the varying degrees of visible fire damage to gypsum wallboard based on its response to heat exposure and visible damage indicators. A scale ranging from 0 to 6 was developed for assigning a DOFD, with 0 indicating no visible damage and 6 indicating complete consumption. Thirtynine "novice" raters performed an analysis of damage to a wall surface, completing 66 ratings first without the DOFD method and second, repeated rating with the new DOFD method. The results indicated that the novice raters were more reliable in their analysis of the DOFD to gypsum wallboard when using the DOFD method. These results support the use of standardized processes to decrease the variability in data collection and interpretation.

\section{Literature on identifying fire patterns}

As one early fire investigation text declares, "patterns are the cornerstone of all fire investigation because of their universal applicability" (DeHaan 1983). It is important to evaluate the evolution of the term fire pattern to better evaluate what literature exists.

Fire pattern was first used to describe how the fire developed or had traveled as described by Kirk, "every fire forms a pattern that is determined chiefly by the configuration of the environment and the availability of combustible material" (Kirk 1969). The term or similar terms were later defined in subsequent texts as "where the fire's destruction took place and where it did not" (DeHaan 1983). In the United Kingdom the use of fire patterns can be found within the literature, though, they tended to discuss these as directional signposts where the "heat flow will cause asymmetric effects within the building" (Cooke and Ide 1985). These early definitions are broad and all encompassing of the entire fire scene. The first attempt at consolidating patterns was the first edition of NFPA 921, however many misconceptions had spawned up between the early 1960's and the publication of NFPA 921 (NFPA 1992).

The Law Enforcement Assistance Administration (LEAA) documented many of the myths about using the visible appearance of damage to identify arson (Boudreau et al. 1977). Arson investigators were surveyed about how they investigate fires and cited interpretation of "burn indicators" as the most common method of establishing arson. Some of these indicators used were alligatoring, crazing of glass, depth of char, lines of demarcation, sagged furniture springs and spalled concrete. The LEAA report, after listing the indicators, identified that these indicators have received little or no scientific testing and that "there appears to be no published material in the scientific literature to substantiate their validity" (Boudreau et al. 1977). Despite the lack of validity and this caution, the training and textbooks within the profession during this time used these indicators as a means to link an observation to the speed of the fire and ultimately to the conclusion of fire cause.

In 1992, NFPA 921's first edition identified most of these old indicators as misconceptions. This first edition was also the first time fire patterns were organized into one document. NFPA 921's original definition stated "fire patterns are the physical effects that are visible or measurable remaining after a fire...including thermal effects on materials, such as charring, oxidation, consumption of combustibles, smoke and soot deposits, distortion, melting, color changes, changes in the character of materials, structural collapse and other effects" (NFPA 1992).

The original definition of fire patterns and how it was used in NFPA 921 was all inclusive of the varying degree of damage to materials, clusters of damage, geometric shapes and the process of using damage to arrive at an area of origin (NFPA 2004). It was not until 2008 that NFPA 921 changed the definition of the term with the introduction of the term fire effects. The definition of fire patterns evolved to "the visible or measurable physical changes, or identifiable shapes, formed by a fire effect or group of fire effects" (NFPA 2008). The definition of fire effects became "observable or measurable changes in or on a material as the result of a fire" (NFPA 2008). Fire 
effects are the bases for the varying DOFD that was discussed in the previous section. This did not so much redefine the NFPA 921 coverage of the topic, but rather clarified the fire investigator's interpretation process in identifying a fire pattern.

The evolution in terminology clarifies how fire patterns became a more restricted definition and it is this bounded term that will be the focus of this literature review section. Prior to discussing the patterns themselves and their historical progression, it is first important to recognize that lines of demarcation or areas of demarcation serve as the borders of a fire pattern and should be defined. Areas of demarcation are locations along a surface that exhibit similar damage characteristics (e.g. magnitude of damage, type of fire effect, color, texture) and are in close proximity to each other. Lines of demarcation are "the borders defining the differences in certain heat and smoke effects of the fire on various materials. They appear between the affected area and adjacent, less-affected areas" (NFPA 2014).

The fire testing conducted for fire patterns has evolved with the changing definition of the term. As such, a subsection on testing is first presented to describe all fire pattern tests conducted, not just those evaluating the current use of the term. The tests were typically conducted to evaluate multiple aspects of using damage for origin determination and not just within the context of clusters of damage, therefore, many of these tests will describe fire effects, clusters of fire effects, fire pattern generation and the use of fire patterns to arrive at an area of origin. The tests will be summarized chronologically in this section and will be referred to in other sections of the literature review where the work specifically addresses that subject matter.

\section{Fire tests conducted related to fire patterns}

All of the fire pattern studies have been summarized in Additional file 1. This spreadsheet provides all of the test details, general instrumentation results, list of indicators identified or not and provides the probability for the identification of these indicators.

The first published fire pattern tests was in 1984 (Custer and Wright 1984). Two $15 \mathrm{ft}$ by $15 \mathrm{ft}(4.57 \mathrm{~m} \times 4.57 \mathrm{~m})$ structures with a ceiling height of $7 \mathrm{ft}(2.13 \mathrm{~m})$ were tested. The compartments were of frame construction with unfinished wood lining the interior of the compartment. There were two windows and one door, where one window was closed and the other open for the fire duration, while the door was opened $5 \mathrm{~min}$ post-ignition. The open window was $3 \mathrm{ft}$ by $3 \mathrm{ft}(0.91 \mathrm{~m} \times 0.91 \mathrm{~m})$ with a sill of $2 \mathrm{ft}(0.61 \mathrm{~m})$ that was directly across the room from the doorway that was $3 \mathrm{ft}$ by $6 \mathrm{ft}(0.91 \mathrm{~m} \times 1.83 \mathrm{~m})$. Both compartments were furnished similarly with a sofa located under the open window, a sofa located along the wall next to the door and a kitchen table in the center of the compartment.

The origin of both fires was located under the window in the sofa, but different accelerants were used to start each test fire with 2-gallons of gasoline in test 1 and scattered newspaper in test 2. A thermocouple tree was located at the area of origin. Each test fire was conducted for $10 \mathrm{~min}$, with the door opened at $5 \mathrm{~min}$. The researchers report negligible winds on the day of the tests. Both tests resulted in an area of greatest damage directly across the room from the window opening, the opposite side of the room from the true origin.

This test was conducted as part of a conference where the participants of the conference were to evaluate the fire scenes for origin. It was reported, "many of the investigators had difficulty finding the location of the point of origin, in many cases indicating the opposite side of the room" (Custer and Wright 1984). The conclusion reached by the researchers was that "it would appear that the major conclusion which can be drawn from this study is that ventilation conditions in the early stages of a fire can cause an anomalous fire spread, thus giving a false impression as to the point of origin" (Custer and Wright 1984). The researchers consequently provide guidance to investigators on how to resolve this situation by saying "it is necessary to pay particular attention to low burns and shadow effects on room furnishings" (Custer and Wright 1984).

In 1997 The United States Fire Administration (USFA), in conjunction with the National Institute of Standards and Technology, Building and Fire Research Laboratory (NIST-BFRL) launched the fire pattern research committee and produced the USFA Fire Pattern Test report (Shanley et al. 1997). This project consisted of 10 separate full-scale tests to produce the first scientifically controlled and recorded research into the formation, growth and investigation of patterns produced in fires. These tests produced the first published data that supported fire patterns as being useful in fire investigation. However, this report also demonstrated that in two tests, "distinctive patterns were produced which without careful study and a full understanding of all factors which influenced the progress and growth of the fire, could easily be interpreted to indicate incorrect or multiple origins" (Shanley et al. 1997).

This study noted that flashover and ventilation was one of the most misunderstood variables, having the influence to alter "normal" fire pattern production. Most notably, "patterns which indicated areas of intense burning but were remote from the point of origin were observed and were determined to be from ventilation effects only. This was observed in rooms, which had flashover conditions where clean burn areas were produced under windows away from the origin. This was also observed on walls opposite door openings" (Shanley 
et al. 1997). Heat and flame vector analysis was used as a process within these studies to document the direction of fire travel, location and magnitude of fire patterns, as well as a process of confirming the area of origin. Again, no procedural details were provided on how to implement the heat and flame vector analysis, but this was the first time that formalized diagrams and legends were published as demonstrative aids.

In March of 1997 four full-size compartment test fires were conducted in furnished bedrooms (Milke and Hill 1997). The compartments were $12 \mathrm{ft}$ by $12 \mathrm{ft}$ with $8 \mathrm{ft}$ ceiling heights $(3.6 \mathrm{~m} \times 3.6 \mathrm{~m} \times 2.4 \mathrm{~m})$ with a single door opening $3 \mathrm{ft}$ by $6 \mathrm{ft}-10$ in. $(0.91 \mathrm{~m} \times 2.1 \mathrm{~m})$. The rooms were instrumented with heat flux gauges, thermocouples and gas sampling probes. The burns were intended to be identical to determine if differences would be discovered with a close analysis of the results. In all cases, ignition of a gasoline spill next to an upholstered chair was used to initiate the fire. The researchers noted differences and attributed these to small variations in the inflow of air.

Another series of full-scale fire tests was conducted with funding provided by the National Institute of Justice (Putorti 1997). Putorti reported, "comparisons of the conditions of the rooms and furnishings after the experiments resulted in the determination of several similarities, as well as many differences, between experiments with the same method of ignition" (Putorti 1997). He attributes the differences to the "ventilation effects".

In 2003, ten full-scale test burns were performed in a ISO 9705 room $12 \mathrm{ft}$ by $12 \mathrm{ft}$ with $8 \mathrm{ft}$ ceiling heights $(3.6 \mathrm{~m} \times 3.6 \mathrm{~m} \times 2.4 \mathrm{~m})$ with a primary focus on examining television sets and electronic appliances exposed to a full-scale room fire (Hoffmann et al. 2003). Six tests were completed with television sets placed inside a wood entertainment center. Two tests were completed with television sets placed on a wood stand next to an upholstered chair. These eight tests were "allowed to continue until just before flashover conditions were attained" (Hoffmann et al. 2003).

The ignition varied where four tests had a $2 \mathrm{ft}$ (0.61 m) diameter pan of Isopropyl Alcohol (IPA) used to ignite a small electrical appliance adjacent to the television set, two tests were ignited by applying the IPA fueled fire directly to the television set and the last two non-full room involvement tests were ignited with the use of newspaper sheets under the cushion and on the floor in front of the upholstered chair. The final two tests were performed after "multiple television sets and electronic appliances were placed on wood stands and on the floor in a burn room containing an upholstered chair and area rug...both of these tests were allowed to progress into full-room involvement and were not extinguished until 4 min past flashover" (Hoffmann et al. 2003).
The researchers stated that one of the objectives of their tests "was to determine if burn patterns in the room were consistent with the origin or location of the external fire" (Hoffmann et al. 2003). The results for the eight tests that did not reach full-room involvement were reported as having "asymmetric fire patterns and heat damage was consistent with the location of the exposure fire for all but one pre-flashover exposure fire test" (Hoffmann et al. 2003). The one test that deviated showed a V-pattern emanating from the floor behind the entertainment center giving the appearance that the "fire origin could be interpreted to be located on or near the floor behind the entertainment center when the fire origin was to the left and along side the television inside the entertainment center" (Hoffmann et al. 2003). The researchers report this deviation in the fire patterns was caused by "the burning, melting and dripping of the plastic electronic appliance next to the television" (Hoffmann et al. 2003).

The two tests that resulted in full-room involvement showed that "burn patterns could be generated which were not indicative of the area of origin of the fire" (Hoffmann et al. 2003). In one of these tests it was found that "other burn patterns in the flashover tests showed similar misleading patterns from asymmetric burning of a television set, with the most damage on the side away from the origin of the fire to patterns on the gypsum walls indicating a $\mathrm{V}$-pattern pointing to a television stand and associated electronics" (Hoffmann et al. 2003). The room burns produced patterns that were both consistent with the origin as well as burn patterns and V-patterns that were inconsistent with the origin.

Beginning in March of 2005, a series of 20 full-scale fire pattern tests were conducted at Eastern Kentucky University (Gorbett et al. 2006; Hopkins et al. 2007; Hopkins et al. 2008; Hopkins et al. 2009; Gorbett 2010; Gorbett et al. 2013). The test fires were conducted in identically constructed, finished and furnished living room and bedroom compartments within a burn building. These studies focused on fire pattern reproducibility, pattern persistence through flashover, the use of fire patterns in origin determination and the influence of initial, low HRR fuel on fire pattern production. The researchers discuss that similar truncated cone patterns were identified in the first eight tests (Gorbett et al. 2006). The most important finding from these tests is that "the interpretation of all fire effects provides substantial evidence for the investigator to identify the correct area of origin" (Gorbett et al. 2010). These studies contended that the use of the heat and flame vector analysis enabled the investigator to determine the true area of origin. Fire effects were listed for each test, fire patterns identified and formal heat and flame vector analysis legends and diagrams were provided for each test. 
However, no procedural details were provided on how to implement the analysis.

In 2005 and 2008, three studies were completed in conjunction with a training seminar to analyze burn pattern development in post-flashover fires (Carman 2008). This study focused on the impact of ventilation on fire patterns and the ability of fire investigators to use fire patterns to determine the quadrant of the room where the fire began. The test was conducted in a single compartment measuring $14 \mathrm{ft}$ by $12 \mathrm{ft}$ by $8 \mathrm{ft}$ high $(4.26 \mathrm{~m} \times 3.66 \mathrm{~m} \times 2.4 \mathrm{~m})$ that resembled a residential bedroom with one open doorway to the exterior. The fire was allowed to burn in postflashover conditions for approximately $2 \mathrm{~min}$. Clean burn damage located on the wall opposite of the door opening (not at the area of origin) extended from the floor to the ceiling and had an approximate 6 -foot base. There was also an area of clean burn with angled lines of demarcation emanating from the area of origin.

Carman (2008) divided the room into four quadrants and performed a survey of the attendees in an attempt to derive an error rate study of investigators. He reports a $5.7 \%$ success rate of determining the correct quadrant where the fire was started. The Carman study did not provide the demographics of the attendees, nor did it provide any statistical rigor. Carman attributed the failure to the lack of understanding by the investigation profession of the differences between pre- and postflashover fire behavior and resulting damage. The authors have since noted several limitations to this exercise including that the participants were not permitted to complete a full investigation of the compartment, were not allowed to move any items and had to make a conclusion based on their visual interpretation of the damage from the doorway.

In 2009, Wolfe, Mealy and Gottuk conducted 15 fullscale tests with varying ventilation conditions and fuels. They focused on under-ventilated fires, the fire growth associated with these types of fires and their forensic analysis. While much of the research was based more on the tenability limits and associated dynamics in underventilated fires, they reported on a few forensic-based conclusions. These included that soot deposition can be used to aid in the area of origin determination and that the clean burn area size was proportional to the fire size (Wolfe et al. 2009).

Carman reports on three tests conducted at ATF's fire research laboratory in a follow-up to his 2008 work (Carman 2010). The three tests were conducted with identical contents and ventilation. The compartment size, ventilation opening and setup were similar to the 2008 work. The three tests were better instrumented with three total heat flux gauges, one radiant heat flux gauge, three gas sensors (measuring $\mathrm{O}_{2}, \mathrm{CO}_{2}, \mathrm{CO}$ ), and gas velocity probes (Oullette 2008). The tests were able to burn in the full-room involvement state for 7, 140 and $111 \mathrm{~s}$ respectively. Each test fire resulted in damage along the wall opposite of the door opening, progressively greater in magnitude with the longer duration in full-room involvement burning. This area of damage opposite the door had angled lines of demarcation that extended from the floor to the ceiling. A clean burn area of damage was located at the area of origin only with the fire with the shortest duration of full room involvement burning. Clean burn damage also occurred along the wall near the doorway opening in the fire with the longest full room involvement burning duration.

A series of nine full-scale studies, funded by the National Institute of Justice, were conducted with ignitable liquid fuel spilled on carpeted and vinyl flooring with varying ventilation scenarios (Mealy et al. 2013). These tests evaluated many aspects of fire investigations, including the presence of ignitable liquid residue after extinguishment, fire patterns, depth of calcination and the fire dynamics of an under-ventilated compartment. A compartment $(3.7 \mathrm{~m} \times 3.7 \mathrm{~m} \times 2.4 \mathrm{~m})$ with a single doorway ventilation opening located in the center of a wall was used for this series of tests. An upholstered sofa and upholstered chair were located in adjacent corners across the room from each other with a coffee table in between. The ventilation opening was located in the wall opposite of this furniture. The ventilation opening was varied throughout the test between a slit vent $(2 \mathrm{~m} \times 0.2 \mathrm{~m})$ and the full door opening $(2 \mathrm{~m} \times 0.9 \mathrm{~m})$. Test one used only Class A fuels, while the eight remaining tests used gasoline as the first fuel ignited. The location of gasoline spilled was varied between the floor and on/around furniture items.

Some of their more notable findings was that floor patterns caused by ignitable liquids may be minimal because they can easily be destroyed, that the commonly reported clean burn damage may be caused by water spray from fire suppression hoselines and that areas of clean burn were associated with the inflow of air due to local ventilation flows. Mass loss of the furniture items was measured at the end of each test and was showed to relate well to the area of origin. Areas along the wall surfaces that were white in color directly adjacent to areas of significant soot deposition were found within this series of tests to be attributed to the oxidation of the soot from the surface (i.e. clean burn) and with wash from the hoseline for suppression. Also, the study illustrated that drywall seams, if no tape and mud was applied, would present areas of clean burn damage during ventilation-controlled conditions (Mealy et al. 2013).

In 2011 three test fires were conducted that varied between single and multiple ventilation openings (Claflin 2014). The three compartments were similarly constructed measuring $11 \mathrm{ft}, 5 \mathrm{in}$. by $11 \mathrm{ft}, 9$ in. $(3.48 \mathrm{~m} \times 3.58 \mathrm{~m})$ with 
a ceiling height of $8 \mathrm{ft}(2.4 \mathrm{~m})$. Each compartment had a door that measured $2 \mathrm{ft}, 7$ in. by $6 \mathrm{ft}, 8$ in. $(0.787 \mathrm{~m} \times$ $2.032 \mathrm{~m}$ ) and was opened to the exterior for the entire duration of the test. Two tests also had a window that measured $3 \mathrm{ft}$ by $4 \mathrm{ft}$ in height $(0.91 \mathrm{~m} \times 1.22 \mathrm{~m})$ with a $2 \mathrm{ft}, 6$ in. sill height $(0.812 \mathrm{~m})$. The compartment was furnished as a residential living room with a couch under the window, armchair directly across the room from the door opening, an office chair adjacent to the doorway and a coffee table.

The origin and ignition of the three tests were in a pillow placed along the back corner of the couch on the floor against the wall with the window. Each fire was said to have only burned for $2 \mathrm{~min}$ in full room involvement. Thermocouple data and total heat flux gauges were used as instrumentation for all three burns. Test 1 had the window and door open for the entire duration of the fire, test 2 had the window hinged closed until flashover and then the window was left opened for the duration of post-flashover and test 3 had no window. These tests demonstrated similar findings as Carman's tests (2008) that significant heat flux and clean burn occurs on the wall directly across the room from the doorway. There was no significant damage identified around the window ventilation, as the researchers discussed that this vent served primarily as an outflow for the heated gases, while the doorway served as the inflow due to the location of the neutral plane. The researchers also concluded that the fire pattern at the true origin persisted in all three tests.

\section{Fire patterns}

This section focuses on the literature that exists for fire patterns. This section has been divided into four subsections that evaluate the general location and type of fire patterns.

\section{Geometric shapes - walls, contents and ceiling patterns} The principle behind fire patterns was first linked to the need to trace the fire spread (Rethoret 1945). All of the early texts indicate that fire tended to rise and that a pattern may exist from this damage, but most did not use the term pattern nor did they give any guidance on what a pattern was (Rethoret 1945; Kennedy 1959; Kirk 1969). The first use of the term pattern was in 1969 by Kirk when discussing the normal behavior of heated gases. However, Kirk elaborated on what the investigator should look for in evaluating this fire pattern when he stated "because of the upward tendency of every fire, some type of inverted conical shape is characteristic, the apex at the bottom being the point of ignition, with the fire rising and spreading" (Kirk 1969). Kirk continues the discussion by cautioning the investigator that this "pattern will be altered by the presence of obstructions, or of readily burned fuel in localized areas," and he warns that a very common complication arises when areas of excellent ventilation are present where "intense burns will be noted in such areas that may well distract the investigator from following the fire pattern back to its point of origin" (Kirk 1969). Consequently, Kirk can be credited as the first person to describe the damage by a fire as a geometric shape.

Kirk's three-dimensional conical shape persists today as the predominant means of evaluating the geometry of fire patterns. Only later did the literature express this conical shape as two-dimensional shapes, including triangular shapes, columnar shapes, V-patterns, U-patterns and hourglass-patterns (Barracato 1979; Cooke and Ide 1985; Kennedy and Kennedy 1985).

The conical fire pattern theory evolved into a more systematized manner by the Kennedys (Kennedy and Kennedy 1985). The system was described as the truncated cone method, which described the fire plume as a three-dimensional cone that would be cut or truncated by the various two-dimensional horizontal and vertical obstructions (i.e. walls, ceiling, contents) within a compartment. The damage that would result would be dependent on the location of the origin of the plume and distance to the intersecting obstructions.

As explained in this method, the two-dimensional shapes and patterns would be formed by the overall three-dimensional plume as it intersected these surfaces resulting in $\mathrm{V}$-shape and $\mathrm{U}$-shape patterns on walls, contents and vertical structural member and Radial-shaped patterns on the ceiling and horizontal obstructions. These researchers proffered that the closer the fuel item burning was to the wall surface, the sharper the contrast and angle to the lines of demarcation and the more likely the damage would resemble a V in shape. The further the fuel item burning was from the wall surface, the lines of demarcation would be more subtle in contrast and would be more round in angle in the shape of a $\mathrm{U}$. Kennedy and Kennedy (1985) were also the first to propose that damage would be in the shape of a triangular, columnar, or conical shape after the flame plume had intersected a wall surface within a compartment.

There are a few misconceptions that have been promulgated over the years associated with $\mathrm{V}$-patterns. The first is that the apex ${ }^{1}$ of the $\mathrm{V}$-pattern indicates an origin (Barracato 1979). Obviously, the damage to the walls remaining after the fire is the cumulative result of all items that burned and the investigator would not be able to tell if the damage witnessed was the first item or a later item burning (e.g. debris fall down). This misconception was dispelled in the first edition of NFPA 921 and is not prevalent within the current profession (Bieber 2014). The other more pervasive misconception dealt with the angle and base of the V-pattern. It was once thought that narrow V-patterns were produced by 
a fast developing fire and wide $\mathrm{V}$-patterns were produced by a slow developing fire (Kennedy and Kennedy 1985). The other misconception stated that if the pattern had a wide base and resembled an inverted cone, then it was started with a liquid fuel (Barracato 1979). Both of these misconceptions have fallen into disrepute and are no longer prevalent within the current profession (Bieber 2014).

Other damage to walls commonly reported, that are not associated with the truncated cone discussion, are referred to as smoke and heat horizons. This damage is commonly reported as heat or smoke deposition reported to be found throughout a structure at varying heights on the walls of a room between areas of no damage and smoke or heat damage. This type of damage was first identified as being helpful at determining the area of origin by Straeter and Crawford (1955). In this text, it is stated that as "heat marks begin to form at the top of a room as a result of the hot air that rises from the fire...these marks get lower and lower on the wall. Wall condition on the four sides of a room may differ and thus indicate where most heat was applied" (Straeter and Crawford 1955). DeHaan elaborated on the characteristics associated with this damage as being "generally level, that is, of uniform height from the floor...changes in the level indicate points of ventilation and the level will often drop markedly in the vicinity of the point of origin" (DeHaan 1983). In over $40 \%$ of the fire pattern tests, level lines of demarcation attributed to this damage was identified.

Truncated cone fire patterns have been found in over $50 \%$ of all fire pattern tests. Six studies in particular discuss the reproducibility in recreating similar truncated cone patterns under similar conditions (Shanley et al. 1997; Hicks et al. 2006; Hicks et al. 2008; Gorbett et al. 2006; Hopkins et al. 2007; Madrzykowski and Fleischmann 2012). A few of the studies also indicated that truncated cone patterns, specifically V-patterns, were located away from the true origin causing confusion for the investigators (Hoffmann et al. 2003; Carman 2008; Carman 2010; Tinsley and Gorbett 2013) (Fig. 6).

Floor patterns Fire patterns identified on the floor have been a common theme within fire investigation as being a possible indicator that flammable or combustible liquids were used within the fire (Smith 1983; Beyler 2009). In fact, a recent sentinel event analysis of wrongful convictions found that this one misconception is the most common factor in wrongful arson convictions (Bieber 2014). This misconception persists despite the warnings from both the fire science and fire investigation communities (Shanley et al. 1997; NFPA 2014; Gottuk and White 2008).

Many of the first texts on fire investigation discussed the concept of low burning and the importance of

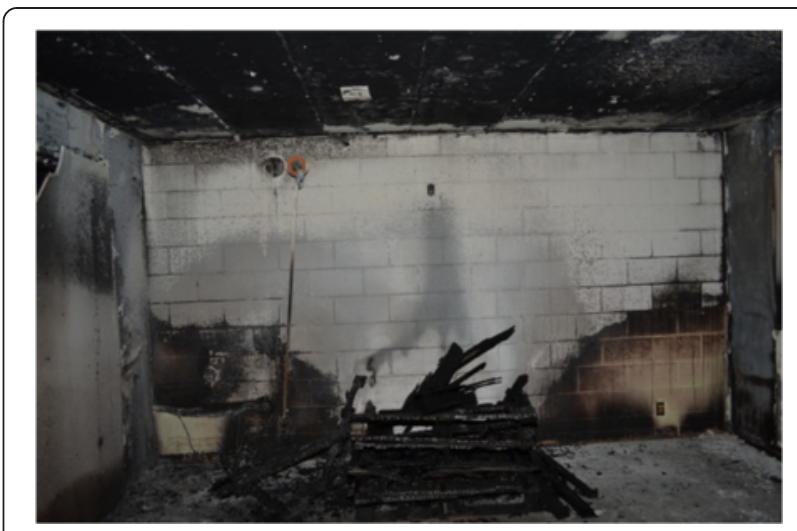

Fig. 6 Photograph of a Conical-Shaped Fire Pattern along a concrete block wall (fire origin was located under the stack of wooden pallets-fire test conducted at EKU by author)

evaluating the floor for fire patterns (Kennedy 1959; Kirk 1969). In these texts the authors stressed that the investigator should evaluate low burns for possible ignition sources, but did not necessarily link the damage to ignitable liquids. In fact, Kirk was very adamant that investigators should not conclude that the damage was from an ignitable liquid as "such an interpretation was more often incorrect than otherwise" (Kirk 1969).

However, other texts of the time indicated that damage to floor was an indicator of arson (Battle and Weston 1960; Fitch and Porter 1968). Obviously this misconception was widespread as Kirk identified that it was "not uncommon for the investigator to assign the cause to the use of a flammable liquid" (Kirk 1969). More than a decade later this misconception can be seen in the majority of all fire investigation literature (Barracato 1979; DeHaan 1983; Smith 1983; Harmer et al. 1983; Kennedy and Kennedy 1985; Cooke and Ide 1985). The majority of these texts stated that the investigator should consider the damage to be caused by an ignitable liquid if the investigator would visibly observe damage to the floor in the shape of a puddle, have hard-edged burn marks in the shape of a pour, or the damage had the appearance of trailers (i.e. long lines of damage appearing to spread the fire from one location to another). However, most of these documents also cautioned against relying solely on the use of visible observations and encouraged the investigator to take samples of fire debris for analysis.

In the mid-1980's there began a trend in the literature that spoke out against this misconception and began to provide a list of alternative explanations of damage to the floor (DeHaan 1983; Taylor 1985; Taylor 1986; DeHaan 1987; Eaton 1987; Wood et al. 2012). The studies demonstrated that the following causes could result in damage similar to irregular floor patterns, including: fires from interstitial space below the floor decking, melting plastics, draperies, furniture items, ventilation 
path and radiant heat from fully developed fires. NFPA 921's original publication followed this trend and warned, "irregular, curved, or 'pool shaped' patterns on floors and floor coverings cannot always be reliably identified as resulting from ignitable liquids on the basis of observation alone" (NFPA 1992). Notice, however, none of these documents came out and directly stated that an investigator could not identify an ignitable liquid from a floor pattern based on observation, they only warned that it "cannot always be reliably identified" (NFPA 1992). This warning was strengthened over the years to say “irregular, curved, or 'pool shaped' patterns on floors and floor coverings should not be identified as resulting from ignitable liquids on the basis of observation of the shape alone" (NFPA 2001).

There have been a few studies performed that specifically evaluated the fire pattern creation on the floor (Putorti 2001; Mealy et al. 2013). Putorti (2001) performed a series of experiments that evaluated the damage to a variety of floor surfaces (carpet, wood and vinyl) with varying volumes of ignitable liquids used in the open. He evaluated gasoline and kerosene. He concluded that it was possible to identify the quantity of fuel used by the burn area. These tests were not conducted within a compartment. Mealy et al. (2013) conducted a series of compartment fire tests with ignitable liquids poured and evaluated the persistence of such a pattern through a compartment fire. They found that that floor patterns caused by ignitable liquids might be minimal because they can easily be destroyed and because the short $\mathrm{du}$ ration of exposure due to fuel consumption.

Floor patterns were found lacking in many of the fire pattern tests where the compartment transitioned to a fully involved state (Shanley et al. 1997; Wood et al. 2012; Mealy et al. 2013). However, some data exists that indicates if a compartment fire does not transition to a fully involved state, then the floor patterns may persist (Putorti 2001; Mealy et al. 2013).

A study conducted in 2012 examined the effect of carpet underlayment/carpet pad on post-flashover fire, floor patterns (Wood et al. 2012). Specifically, the hypothesis that carpet pad seams could mimic the floor fire patterns previously attributed to ignitable liquid pours was examined. Fire tests in a scaled compartment using a propane sand-burner were designed to rapidly progress through flashover with a short period of full room involvement. Instrumentation included thermocouples in the gas layer and under the flooring material. Multiple carpet pads were tested. Carpet pad configuration was also varied including no seam and two, off-center seams for comparison and control purposes. Additional comparison and control samples were generated using ignitable liquid pours that achieved post-flashover conditions without use of the burner, but with the burner in place to maintain test consistency. A subset of replicate tests was also performed. Post-test data collection included examination, photography and a subset of depth of char measurements. Preliminary results indicated the ability to generate similar although not identical floor burn patterns between carpet pad seams and ignitable liquid pours (Figs. 7, 8 and 9).

Undamaged areas The lack of damage has often times been overlooked in most discussions related to fire patterns. The investigator has always been tasked to evaluate damage from lesser to greater with minimal advice related to any meaning that exists for the lack of damage or the lesser damaged areas (Rethoret 1945). Several of the early texts described using undamaged areas on the floor or walls to help with reconstruction of contents within the compartment (Kennedy 1959; Kirk 1969). This is still a common practice in fire investigations with these undamaged areas termed protected areas.

Custer was the first to discuss a concept of shadowing by content items and how these areas of lesser damage assisted the investigator in identifying direction of heat exposure (Custer and Wright 1984). Later the term morphed into heat shadowing, which was first defined as "the effect of an object blocking the convected or radiated travel of heat and flame from its source to the particular surface material which is under examination" (Kennedy and Kennedy 1985).

Heat shadowing and protected areas were shown to assist investigators in determining that the fire did not originate behind certain contents (Shanley et al. 1997; Gorbett et al. 2013; Claflin 2014).

Penetrations Holes in floors have had many misconceptions tied directly to floor patterns, as discussed previously. The same proponents of identifying 'pour patterns' as being indicative of an ignitable liquid, also promulgated that holes in floors were indicative of ignitable liquids

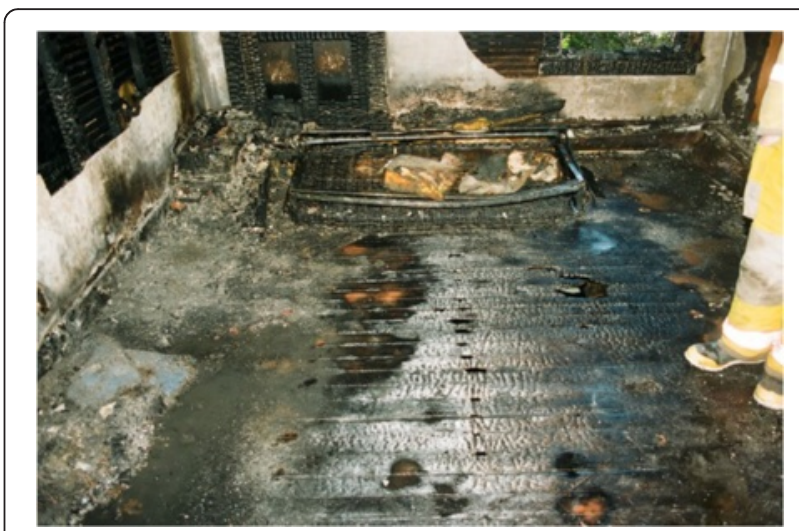

Fig. 7 Scene photograph of suspected ignitable liquid pour (Wood et al. 2012) 


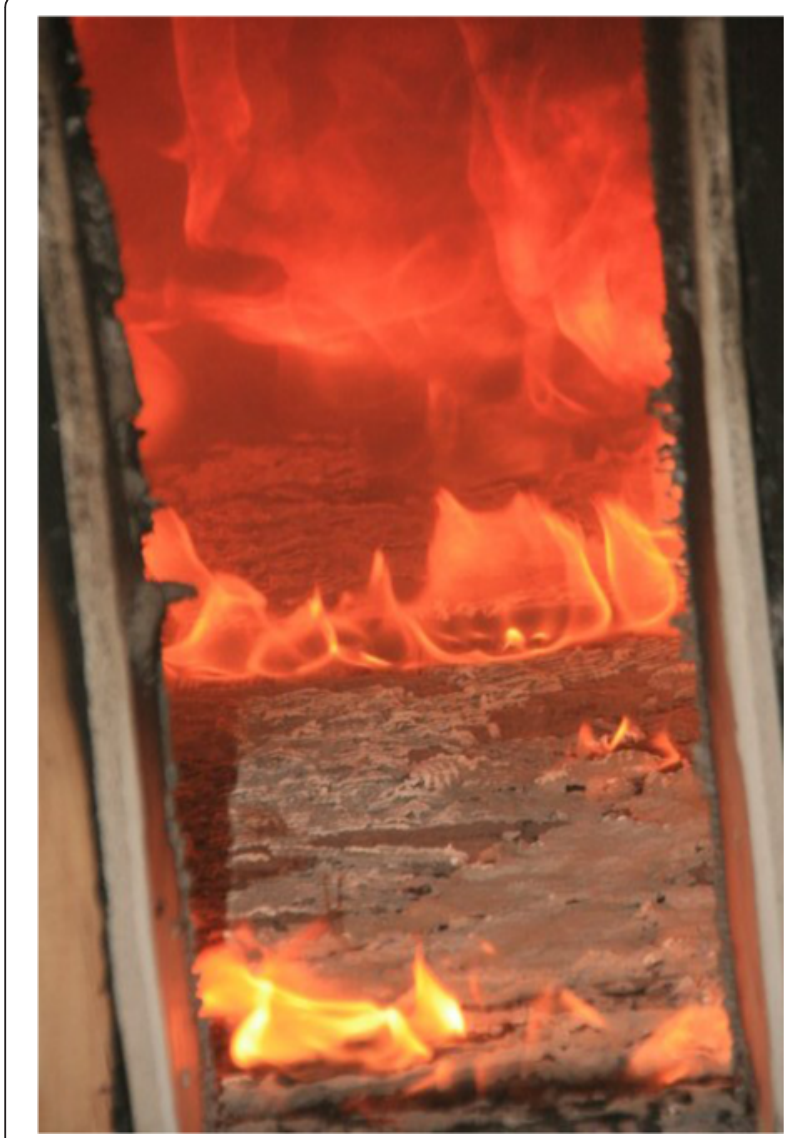

Fig. 8 Testing photograph for carpet pad seam generation of pattern similar to reported ignitable liquid pour showing burning in exposed surface resulting from carpet pad shrinkage (Wood et al. 2012)

being used (Battle and Weston 1960; Fitch and Porter 1968; Barracato 1979; Smith 1983; Harmer et al. 1983; Kennedy and Kennedy 1985; Cooke and Ide 1985). Kirk being one of the few texts at the time that opposed this idea when declaring "flammable liquids never carry fire downward" (Kirk 1969). As floor patterns were warned

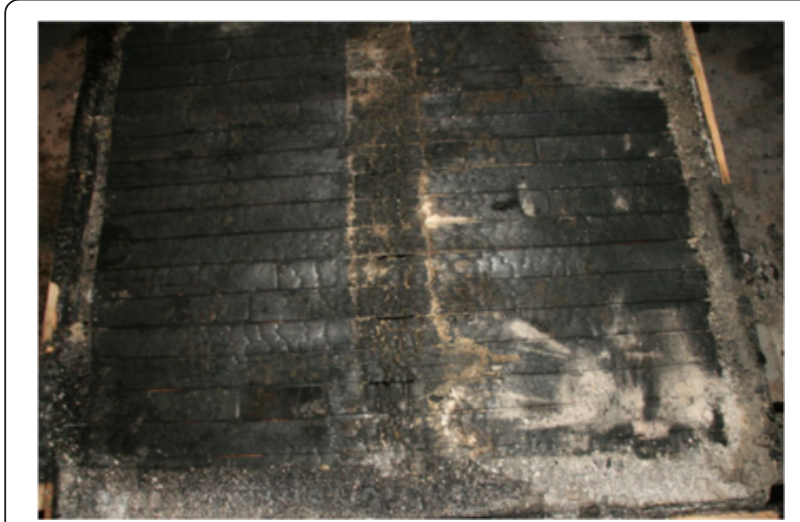

Fig. 9 Resultant floor burn pattern from carpet pad seam without use of ignitable liquids (Wood et al. 2012) against, so has floor penetrations by both the fire science and investigation communities (Babrauskas 2005; NFPA 2014). Alternative explanations are now commonly given when discussing penetrations through floors, including: radiant heat, furniture items, melting plastics and preexisting openings in the floor during fully involved compartment fire (NFPA 2014) (Fig. 10).

Other penetration patterns have arisen, which dealt more with determining the direction of fire spread from top down or bottom up. There have been many references to penetrations through floors within the early texts on fire investigations, but few provided any guidance on how to interpret from the damage if the fire was moving up through the hole or down. The first discussion on this came in the form of discussing beveling or loss of mass (DeHaan 1983). Illustrations from this first discussion are still found today in the current edition of NFPA 921 showing a cross-section of a floor with greater beveling or loss of mass indicating direction (NFPA 2014). The current damage indicator as espoused by NFPA 921 is that "sides that slope downward from above toward the hole are indicators that the fire was from above. Sides that are wider at the bottom and slope upward to the center of the hole are from below" (NFPA 2014).

Babrauskas (2005) lists several unpublished tests of holes through wood floors and provides a summary of these tests.

\section{Literature on compartment fire dynamics influencing damage}

The damage observed to wall, ceiling and content surfaces is an artifact of the fire dynamics for that fire. Identifying the cause of the damage is complicated by the fact that the investigator has to use evidence after the event, such as the location and magnitude of damage, compartment geometry, ventilation openings and the position and number of fuels as a means to identify the range of initial conditions that may have influenced how the fire developed. Because of this, the problem of using

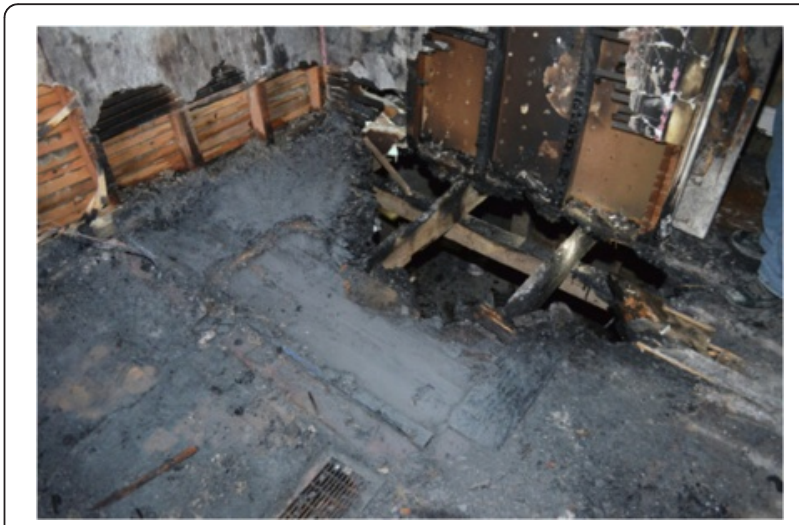

Fig. 10 Photograph of penetration through a floor 
fire damage to determine how the fire developed is considered an inverse problem. Other areas of science regularly deal with inverse problems typically through extensive mathematical study. However, most inverse problems are approached by first establishing direct solutions for well-posed problems. Therefore, the approach of this step is to leverage what science currently exists to assist with validating the current list of direct solutions for fire pattern generation and identifying characteristics that may exist and how they may vary with the changing fire dynamics. The direct solutions currently listed for causes of fire patterns include, plume-generated patterns, hot gas layer-generated patterns, ventilation-generated patterns and suppression-generated patterns (NFPA 2014).

In this section of the literature review, sections 2.3.1.1-2.3.1.2 discuss the basic causes of fire patterns and will serve as the connection of fire investigation terminology to the fire science research that has been conducted in those areas. Section 2.3.2.1-2.3.2.5 will outline the characteristics that are currently being used by fire investigators in determining the cause of the fire pattern and evaluate the findings of the fire pattern studies.

\section{Causes of damage}

The investigator typically assigns an interpretation to each fire pattern as to how it may have been created, which in turn assists the investigator in determining how the fire spread. This process has significant potential for uncertainty, as the initial conditions are generally unknown to the investigator.

NFPA 921 states that there are "three basic causes of fire patterns: heat, deposition and consumption" (NFPA 2014). Consumption is a function of heat transfer and the material properties. As such, material properties were already discussed in the degree of fire damage assessment and will not be duplicated here.

Cause of damage - heat The cumulative heat exposure should be considered the leading factor in the creation of damage. The cumulative heat exposure consists of the duration and varying intensity of heat exposure to the materials. Heat exposure to the materials (e.g. plastics, wood) will result in either physical or chemical changes. Physical changes include melting, deformation, expansion, or loss of tensile strength. Chemical changes include the decomposition/pyrolysis, dehydration, or changes in color.

Heat damage to the surface linings and the contents within the compartment after the fire is frequently the most readily visible and measurable. The effects that remain after a fire are typically related to the damage resulting from the cumulative heat flux received by an exposed material. The developing fire and the variables influencing the fire scenario control heat transfer in a compartment, including the location, the intensity and duration of the heat transfer. The dominant sources for heat transfer during a compartment fire stem from the following:

1. Flaming Combustion

a. Fire plume associated with a burning fuel item/ package

b. Flame spread over/through a material

c. Diffusion flames where the fuel and air mix at the combustion site (i.e. flaming combustion detached from the fuel item or package)

2. High temperature combustion gases

a. Ceiling jets

b. Upper layer gases

3. High Temperature lining surfaces - Radiant heat transfer (absorption/reflection)

As heat transfer is first and foremost dependent on a temperature difference, greater temperature differences will result in greater heat flux. In a compartment fire, the highest temperatures are present at those locations where flaming combustion is occurring. The fire plume and the various heat fluxes generated by it are one of the primary means of damage production in the early stages of a fire due to this great temperature difference and highly turbulent flows. Fire plumes against wall surfaces have shown to have moderate heat fluxes ranging from 40 to $80 \mathrm{~kW} / \mathrm{m}^{2}$, while heat fluxes measured in tests with objects immersed in diffusion flames range between 75 and $200 \mathrm{~kW} / \mathrm{m}^{2}$ Heskestad (1982); (Qian and Saito 1992; Dillon 1998; Lattimer 2008). Incident heat flux to wall, floor, or ceiling surfaces is dependent on the HRR of the fuel and standoff distance between the flame plume and the surface of interest. The greater the distance between the base of the plume and the surface of the wall or content surface will result in a substantially decreased heat flux to the surface (Qian and Saito 1992). Saito (1993); Williamson, et al. (1991) witnessed a 50-70 \% decrease in peak heat flux values when small standoff distances $(0.05-0.25 \mathrm{~m})$ were employed.

The flame plume is also the most predominant contributor to damage and ignition of secondary and tertiary contents early in the fire prior to the contribution by the upper layer (Jahn et al. 2008). There has been much work towards developing methods for calculating the radiant heat transfer from a plume to secondary objects outside of the plume with varying accuracy. The bulk of this research can be found within the SFPE Engineering Guide, "Assessing Flame Radiation to External Targets from Pool Fires” (SFPE 1999). Many calculations are focused on simplifying geometric shapes, such as cylinders, cones, planes and point targets.

One aspect of looking at radiant heat flux is to determine if the secondary object has been raised to a critical 
temperature or is receiving a critical heat flux where ignition of that object is possible. In the fire investigation profession, testing to determine whether the first burning object can ignite a secondary object is paramount to hypothesis testing of an area of origin. Equally important is to determine whether the radiant heat transfer is sufficient to cause damage to nearby contents or wall surfaces.

Some experimental work has been conducted in this area as well as predictive calculations (Jahn et al. 2008). Theobald (1968) performed a series of experiments with target combustible items (wood blocks, cotton cloth and plywood) located at $0.45 \mathrm{~m}$ and $0.9 \mathrm{~m}$ above the floor at various lateral distances away from a variety of common residential fuel items burning, such as a kitchen chair, easy chair, arm chair, bookcases and wardrobes. He then recorded the maximum lateral distances at which the target fuels were scorched, charred, or ignited. Items were scorched at distances greater than $0.19-1.2 \mathrm{~m}$ depending on the material and heat source.

Babrauskas (1981) reports on ignition of secondary items based on burning a series of common residential fuels and evaluating the heat flux to transducers at varying lateral distances. He reports

"irradiances measured $0.05 \mathrm{~m}$ away range to near $80 \mathrm{~kW} / \mathrm{m}^{2}$ for the fastest burning specimens; however, $40 \mathrm{~kW} / \mathrm{m}^{2}$ was not recorded farther than $0.44 \mathrm{~m}$ away and $20 \mathrm{~kW} / \mathrm{m}^{2}$ was not found beyond $0.88 \mathrm{~m}$ distant. The implication is that common furnishing items, which normally require a minimum irradiance approaching $20 \mathrm{~kW} / \mathrm{m}^{2}$ for ignition, would stand little hazard of fire involvement if placed at least $1 \mathrm{~m}$ away from the initial source" (Babrauskas 1981).

These findings were reported as only being applicable for pre-flashover fires. More recent research has identified heat flux values between 25 and $50 \mathrm{~kW} / \mathrm{m}^{2}$ reported at $1 \mathrm{~m}$ away from more modern fuel packages, including king size mattresses, upholstered chairs and sleeper sofas (Madrzykowski and Kerber 2009).

The collection of high temperature gases within a compartment is also a source of heat flux that can cause damage. A ceiling jet is formed by the intersection of the plume with the ceiling, which will cause greater heat to be transferred first to the ceiling surface and later to the intersecting wall surfaces. The temperature of the plume will be greatest near the plume centerline and therefore the greatest heat flux to the ceiling surface will be at this location at this point throughout the duration of the fire. The temperature and resultant heat flux decreases with increasing radial distance from the plume centerline. In addition, the ceiling jet velocity is highest near the centerline of the plume and decreases as it moves outward (Heskestad 2008). Consequently, these two factors combine to inflict more damage and create more pronounced fire effects near the plume centerline, with the damage decreasing as the distance from the centerline is increased (Jowsey 2007). When the flame plume has not intersected the ceiling, heat fluxes along the ceiling surface near the centerline of a plume have been recorded to range between 80 and $100 \mathrm{~kW} / \mathrm{m}^{2}$ within $0-1 \mathrm{~m}$ radial distance, while heat fluxes between 1.0 and $1.6 \mathrm{~m}$ radial distances ranges between 10 and $70 \mathrm{~kW} / \mathrm{m}^{2}$ (Dillon 1998; Lattimer and Sorathia 2003).

As the fire continues to develop, the ceiling jet and the gases from the upper layer begin to have an intensified effect on the surfaces nearest the plume. Later in a fire's development, an upper layer begins to form and starts transferring heat to the wall and ceiling surfaces. The energy generated by the fire and therefore the temperatures and layer depth of the upper layer vary as a function of time (Walton and Thomas 2008). Thus, different locations within the compartment may be receiving different temperatures at different times throughout the fire. However, an assumption can be made for fuel-controlled fires that higher temperatures will occur at the plume interface with any building or content's surface. As the temperature of the gases in the upper layer increases and the duration of influence between these gases and the lining surfaces increase, the heat flux imposed on these surfaces reaches a critical threshold that begins damaging the material and creating fire effects attributed to the upper gas layer. Heat fluxes to the walls inside a compartment containing an upper gas layer have been reported to range between 5 and $40 \mathrm{~kW} / \mathrm{m}^{2}$, based on varying temperatures between 200 and $600{ }^{\circ} \mathrm{C}$ (Tanaka et al. 1985).

Drysdale (2011) indicates that the average compartment temperatures are highest near the cross over between fuel-controlled and ventilation-controlled. The fires that are located at the extremes of the spectrum (i.e. predominantly fuel-controlled or ventilation-controlled) produce substantially lower temperatures. Consequently, the damage expected in a fuel-controlled state is generally lesssevere until the ventilation begins deteriorating, nearing the cross over to ventilation-controlled. Furthermore, average fire gas temperatures have been related to the ventilation factor compared to the total surface area of the compartment, commonly denoted by $A_{v} \sqrt{H_{v}} / A_{T}$. This relationship points out that there are higher gas temperatures reached in the fuel-controlled burning but the duration of burning is shorter because "much of the heat energy is transferred out of the room by the air/fire gas exchange" (Drysdale 2011).

There has been extensive work done in the area of flashover for traditional residential-sized compartments with a single opening. Several correlations have been developed to assist in determining the minimum HRR necessary for 
flashover to occur, conditioned on the total surface area of the compartment $\left(\mathrm{A}_{\mathrm{T}}\right)$ and the ventilation factor $A_{v} \sqrt{h_{v}}$ (McCaffrey and Quintiere (1977); Babrauskas 1980; McCaffrey et al. 1981; Thomas 1981). As the compartment transitions through flashover and into full-room involvement, the upper layer descends toward the floor and encompasses nearly the entire volume of the compartment. Therefore, the walls, ceiling and floor surfaces are now receiving an elevated heat flux, in addition to the already burning fuel receiving greater feedback, increasing its own HRR and other fuels becoming involved. A common maximum recorded heat flux in a postflashover compartment fire is $170 \mathrm{~kW} / \mathrm{m}^{2}$ (NFPA 2014). Each fire pattern study has the three most common flashover correlations summarized within Additional file 1.

During a fully involved compartment fire or when a compartment fire is ventilation-controlled, more complete combustion is achieved at those locations where the mixture is adequate. Several studies concerning ventilationcontrolled fires throughout the years have introduced a concept of a ventilation factor $\left(A_{v} \sqrt{h_{v}}\right)$ and illustrated the importance of ventilation openings on a fire's growth by analyzing the size of ventilation openings, locations of these openings within the compartment and the shear mixing that occurs at the interface of the opening (Kawagoe 1958; Thomas and Heslden 1972; Harmathy 1972; Thomas and Bennets 1999; Utiskul 2007; Sugawa et al. 1989; Quintiere 1995). Many of the studies discuss the production of unburned hydrocarbons (UHC's) during underventilated conditions that result in unburned fuel filling the compartment and undergoing combustion only where sufficient UHC concentrations encounter sufficient oxygen (Beyler 1986; Utiskul and Quintiere (2005); Utiskul 2007; Thomas and Bennets 1999).

Not all compartment fires will transition through flashover (Drysdale 2011). The compartment can reach a state of full-room involvement without transitioning through flashover, or become ventilation-limited and never achieve full-room involvement state (Francis and Chen 2012). One of the most important findings is that combustion was found to occur detached from fuel items and found to burn nearest the open ventilation source if the global equivalence ratio $(\phi)$ in the fire room becomes larger than unity, typically between 1.2 and 1.6 depending on temperature (Thomas and Bennets 1999; Utiskul 2007). $\phi$ is defined as the average fuel-to-oxygen mass ratio in a compartment divided by the stoichiometric value in a compartment (Wieczorek et al. 2004).

The fire is generally regarded as well-ventilated when values of $\phi<0.3-0.5$. The combustion within this compartment is of a high efficiency and the yields of soot and carbon monoxide (CO) are low (Pitts 1994). The fire is considered to be under-ventilated at higher values of $\phi>1.0$. Typically, flashover occurs at a $\phi=1.0$ (Wieczorek et al. 2004). Gottuk (1992) reports sustained external burning occurring at $\phi$ values around $1.4+/-0.4$, but other research has reported extension of flames outside the compartment starting at $\phi$ values of 0.7 (Wieczorek et al. 2004). Gottuk's (1992) results were gases from the layer burning and escaping, while Wieczorek et al. (2004) had flames resulting from a lack of mixing within the compartment, which has also been identified in compartments with combustible linings (Drysdale 2011). As the combustion zone is not attached to a fuel item or fuel package any longer, it becomes more difficult for the fire investigator to evaluate whether the damage was caused by a flame plume burning attached to a fuel item or if it is the UHCs burning detached from a fuel item due to ventilation-controlled conditions. Therefore, determining if and when the fire transitions from a fuel-controlled to a ventilation-controlled condition is an important distinction.

As the effects of ventilation have been shown to significantly influence damage within the compartment, a further review of these concepts is necessary. Hydrostatic pressure differences at the ventilation opening cause the hot gases to exit the compartment and cooler air to be transferred into the compartment, assuming no external force is causing a greater pressure. The natural convection drives air out of the compartment creating a lower pressure for inflow to be driven from gravity flows or can also be influenced by wind or other mechanically induced flows (e.g. positive pressure ventilation). The mixing of the air and UHCs has been shown to occur at the opening, along the gravity flow, around objects within the flow and opposite the opening along walls, specifically for doors (Abib and Jaluria 1992a, b; Quintiere and McCaffrey 1980).

Quintiere and McCaffrey (1980) showed that nearopening mixing associated with the cold, incoming air flow entraining the hot gas is an issue that would be a potential cause for near-to or adjacent damage occurring on surfaces next to ventilation openings. Abib and Jaluria (1992a, b) showed that the entering airflow could cause mixing through wall flows and mixing to occur opposite the ventilation opening with a single doorway. The velocity of this air inflow also influences this mixing.

The average velocity of natural buoyancy driven flows or natural ventilation through the bottom of a door during ventilation-controlled conditions is approximately 1.5-2.0 m/s (3.4-4.4 mph) (Kerber 2010; Quintiere and McCaffrey 1980). Average velocities of natural ventilation flows through windows have been recorded between 0.5 and $1.0 \mathrm{~m} / \mathrm{s}(1.1-4.4 \mathrm{mph})$ depending on the sill height and elevation of the opening within the wall (Kerber 2010; Kerber and Walton 2005; Quintiere and McCaffrey 1980). The square root of height of the opening is the relevant 
determinant of the max velocity (Babrauskas 1980; Quintiere 1995). The reported velocity of flows from wind-assisted or mechanically induced flows through the bottom of a door and window can be on the order of $10 \mathrm{~m} / \mathrm{s}(22 \mathrm{mph}$ ) (Kerber and Walton 2005; Madrzykowski and Kerber 2009).

Other factors that have been shown to influence the HRR within a compartment and the location of combustion are suppression-related activities that affect ventilation. The ventilation of the compartment for suppression is a common activity by fire department personnel, typically performed by opening doors and windows. Often times, positive-pressure ventilation, or mechanically induced ventilation, through the use of a fan is employed in conjunction with fire suppression activities. This change in ventilation is typically done during ventilation-controlled conditions, which causes the HRR to increase within the compartment and results in combustion wherever the mixture of UHCs and oxygen is sufficient and that the mixture be at a sufficient temperature to initiate combustion (Madrzykowski and Kerber 2009; Kerber and Walton 2005).

Cause of damage - deposition Exposure of materials to the byproducts of combustion can also lead to damage that may be useful to the investigator. Smoke contains particulates, liquid aerosols and gases (NFPA 2014). The deposition of smoke/soot onto surface linings and contents within an enclosure stems from the following:

1. Fluid flows - Temperature and velocity of the gases colliding with cooler surfaces (thermophoretic forces).

2. Distance from the area(s) of combustion

Combustion that fire investigators will most commonly encounter is predominantly diffusion flames. The combustion of a fuel through diffusion flames is inherently oxygen limited by the diffusion reaction and the availability of only $21 \%$ of oxygen in air in wellventilated fires. This limitation of the flaming combustion allows for the production of smoke. Smoke consists of liquid aerosols, solid particulates (i.e. soot), and gaseous byproducts, including carbon monoxide (CO), carbon dioxide $\left(\mathrm{CO}_{2}\right)$, hydrogen cyanide $(\mathrm{HCN})$, oxygen $\left(\mathrm{O}_{2}\right)$, steam $\left(\mathrm{H}_{2} \mathrm{O}\right.$ vapor $)$, and unburned hydrocarbons (UHC). This production of incomplete combustion byproducts is exacerbated in poorly ventilated spaces, ventilation-controlled burning regimes and combustion of fuels that under normal atmospheric conditions have high soot yields (e.g. aromatic and unsaturated hydrocarbons).

The liquid aerosols, soot and other particulates are in motion due to the buoyant nature of the heated gases. As this smoke collides with cooler surfaces, it may deposit out of the heated gases onto wall, ceiling and content surfaces. The amount of soot deposited is dependent greatly on the thermophoretic forces and by soot losses throughout the building (Riahi and Beyler 2011; Riahi 2012; Riahi et al. 2013; Wolfe et al. 2009).

Thermophoretic forces between the gas and surface lining are greatly dependent on the burning regime of the fire. In the early stages of a fire and through fuelcontrolled conditions, the production of the incomplete combustion byproducts ( $\mathrm{HCN}, \mathrm{CO}, \mathrm{UHCs})$ is typically minor. The production increases substantially as the compartment fire becomes ventilation-limited. The higher temperatures and higher velocities of smoke cause greater collection of soot deposits to form in certain locations within the compartment. As the temperatures are higher in the room of origin it is expected that an upper layer will be affecting those surfaces higher in elevation. Conversely, as the smoke moves away from the room of origin the temperatures will decrease, which causes the smoke to descend within the compartment causing lighter soot to deposit across the entire elevation of wall surfaces. Therefore, it is expected that soot deposition on wall surfaces to be greatest in thickness and higher in elevation closer to the room of origin and lesser in thickness and lower in elevation as one moves away from the room of origin. Often times the soot deposited within the room of origin will be higher in elevation with distinct lines of demarcation and thick soot deposits. Soot deposited in rooms away from the room of origin have a fairly uniform soot deposition on all surfaces extending from floor to ceiling (Wolfe et al. 2009).

Riahi (2012) studied the soot deposition characteristics of three different fuels in bench-scale experiments and then against a gypsum wallboard lined wall. An optical measurement method was developed to arrive at optical properties of smoke deposited out of a smoke layer onto glass filters. From this work, the researchers used gravimetric measurements of these filters to demonstrate and validate an analytical model for smoke deposition based on thermophoresis.

\section{Characteristics of direct solutions}

The characteristics of damage that have been reported in the literature to assist investigators in determining the cause of the fire pattern will be evaluated here.

Plume-generated fire patterns (PG Patterns) Fire plume generated fire patterns are the most important to identify correctly. The fire origin will ultimately be connected to a plume generated fire pattern. However, if the fire pattern is incorrectly assigned as a plume generated pattern, then the entire origin hypothesis will most likely be incorrect (Carman 2008).

The fire plume is typically the highest temperature zone within the compartment, which can lead to significant 
damage (Beyler 1986; Lattimer 2008). In fuel-controlled fires, the greatest damage within the compartment is typically found near fuel item(s) or fuel package(s) that have undergone combustion. As discussed in Section 2.3.1.1, those surfaces that have direct flame contact will have the highest heat flux exposure, followed by fire plumes near surfaces. However, all of this is dependent on the burning regime and where combustion is actually taking place at the point in time during the fire when the fuel was ignited.

As with anything, there are additional caveats in the identification of plume-generated fire patterns. The first of which is the standoff distance between the fuel item burning and the damaged surface. Shanley et al. (1997)) reported one of the driving factors for the lack of a plume-generated fire pattern associated with the origin in a chair was due to the chair being placed approximately 18-inches away from the wall.

Plume-generated fire patterns are commonly associated with a greater magnitude of damage (NFPA 2014). Therefore, the fire effect itself may provide a basis for determining what degree of heat flux and/or duration is required to cause the effect. For example, many materials must reach certain temperatures to melt, deform, or fail. If the temperatures are high enough to cause such damage, then it is likely that a plume caused the effect. For example, the clean burn effect requires wall temperatures to reach approximately $450-500{ }^{\circ} \mathrm{C}$ and should be evaluated as possibly exposed to a plume (Stratakis and Stamatelos 2003).

NFPA 921 (2014) discusses that plume-generated patterns typically have characteristics associated with geometric shapes. Fire investigators have used geometric shapes, such as truncated cones, triangular, columnar, conical, v-shaped, u-shaped and hourglass-shaped patterns since the early 1940's (Rethoret 1945). Every fire investigation text, including NFPA 921, uses shapes to describe the characteristics of the lines of demarcation associated with plume-generated patterns. There are only two studies that have focused solely on the geometric shapes from plumes (Hicks et al. 2006; Hicks et al. 2008); although, most fire pattern studies listed in Section 2.2.1 use shapes as descriptors.

Dillon (1998) indicated that one could generalize a simplified flame shape based on a series of ISO-9705 room corner tests by using the average incident heat flux of $30 \mathrm{~kW} / \mathrm{m}^{2}$. He found that the damage from the flame plume would extend approximately the width of the fuel for $100 \mathrm{~kW}$ fires that did not have a ceiling jet form and 3 times the width of the fuel with $300 \mathrm{~kW}$ fires that did have flame extension under the ceiling. Dillon (1998) went on to illustrate that some of the corner flame height approximations resulted in $40 \%$ uncertainty, but others were as close as $2 \%$.
Madrzykowski and Fleischmann (2012) completed work on flame plume damage against a gypsum wallboard lined wall and showed that for smaller HRR fuels (20-80 kW) the maximum width of damage was never greater than 1.5 times the width of the fuel. His work also determined that the height of the plume damage was within $5 \%$ of the mean visible flame heights for the natural gas burner and gasoline fires. Comparing Delichatsios's (1984) simple correlation of flame height for wall fires to the average damage height identified in Madrzykowski's study shows that the calculated flame height under-predicted the damage height by approximately $7-11 \%$ for the natural gas burner and gasoline fires.

Fire investigation texts describe the characteristics of the lines of demarcation associated with a plumegenerated pattern as a progression through triangular, columnar and conical patterns. The inverted cone or triangular pattern resembles an upright triangle with the vertex at the top. This pattern has been associated with a fuel package that has the potential HRR to overcome the thermal inertia and start a pyrolysis reaction in the surface material, thereby creating the pattern, but insufficient energy to produce a plume which reaches any horizontal restriction above the fuel package (Hicks et al. 2008; Madrzykowski and Fleischmann 2012; NFPA 2014). This has been provided as the reason for a visible area remaining that exhibits heat exposure, which has a sharp leading edge of demarcation widening significantly at the base forming a triangular shape or pattern.

Largely parallel vertical lines of demarcation and a HRR sufficient to reach any horizontal restriction above the fuel package have been provided as the reason for columnar patterns (NFPA 2014). A columnar pattern has been described as a visible pattern where the leading front, or sharp leading edge of demarcation from a triangular pattern, has continued to spread with the rising heat and other products of combustion and has reached an intersecting horizontal surface (Hicks et al. 2008).

A conical pattern has been characterized as one that is produced when the interacting buoyant fire plume is restricted by an intersecting horizontal surface, spreading the heat across the bottom of the obstructing surface. The surface then redirects the buoyant flow and its momentum across the bottom of the ceiling creating a ceiling jet, which begins to descend from the ceiling as an upper layer (Hicks et al. 2008). This causes the plume to widen horizontally in the upper layer causing damage to the intersecting surfaces. A two-dimensional fire pattern is expected to form on the vertical surface interface (i.e. walls) in the form of a funnel or cone with the vertex at the bottom. This fire pattern has been proposed to indicate a fuel package that has reached a HRR sufficient to create a flame plume that reaches the horizontal surface (i.e. ceiling). 
As vertical and horizontal surfaces intersect this 3-D fire plume, truncated conical shaped patterns have been shown to form (NFPA 2014). If the burning fuel package was located at or very near the vertical witness surface, then the expected fire pattern is shaped as a "V", evidenced by its angulated lines of demarcation. If the burning fuel package was located away from the witness surface, the resulting fire pattern has been characterized as being in the shape of a " $U$ ", evidenced by its radial or curved lines of demarcation (Hicks et al. 2008; NFPA 2014).

Several myths have been associated with geometric shapes that cause investigators pause before using the shapes as descriptors. For example, one myth was that an investigator could determine the speed of the fire by looking at the width of the v-pattern. Another myth is that at the base of every $v$-pattern is an origin. These myths have been dispelled by several studies, but their influence on using the geometric shapes as descriptors has justifiably persisted (NFPA 2014; Shanley et al. 1997).

Another problem is that the shapes discussed are assuming an idealized fire plume that is shaped as a cone, which is a gross oversimplification. Shanley et al. (1997)) described the phenomenon that ventilation to the room was able to change the truncated cone shape expected from the flame and fire plume by "leaning or pushing of one side of the pattern away from the source of ventilation" (Shanley et al. 1997). Airflow from a ventilation opening has been shown in previous compartment fire studies to cause flames to lean over significantly and that the influence of this factor decreases as the plume is moved back away from the vent (Steckler et al. 1982; Mealy et al. 2013). As such, the recognition and identification of lines or areas of demarcation and the elevation changes with those lines of demarcation capture the essence of these shapes without using geometric shapes as universal descriptors.

In summary, the characteristics distilled from the literature is that plume-generated patterns have areas of greater magnitude of damage in relationship to the surrounding areas and because of this the lines of demarcation between these areas are described as clear or sharp. Also, the lines of demarcation are not parallel to the floor or ceiling, but are at an angle representing the buoyant flow, usually with characteristic geometric shapes (Fig. 11).

\section{Upper layer-generated fire patterns (ULG Patterns)}

The upper layer is a term commonly given to the collection of smoke and heated gases during the progression of the fire near the upper regions of the compartment, typically near the ceiling. The high temperature gases and soot in the upper layer influences the patterns

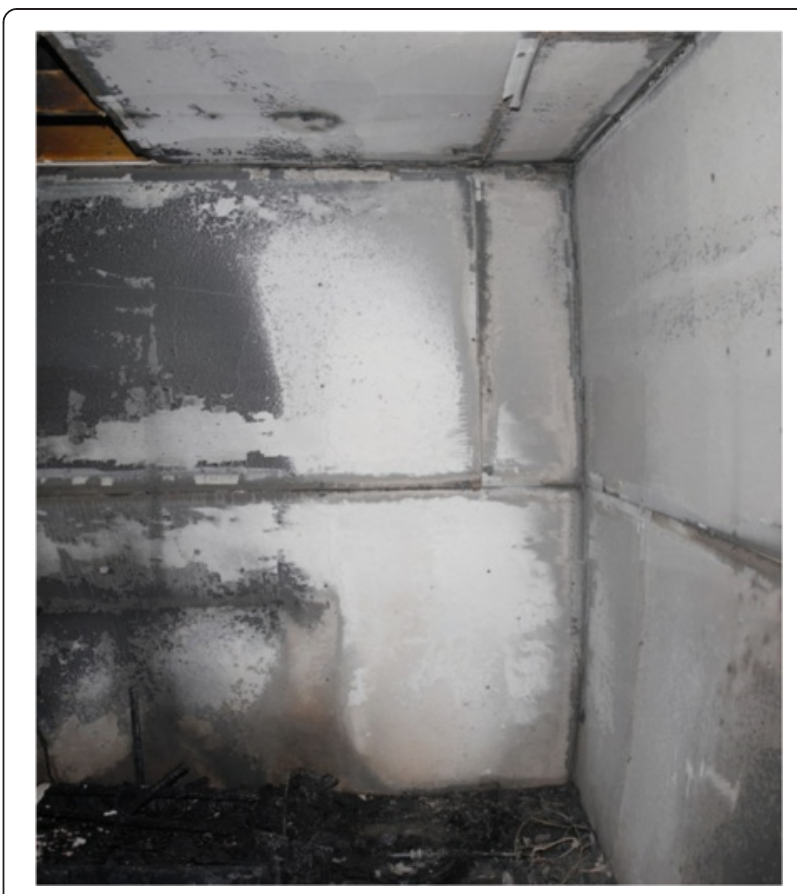

Fig. 11 Photograph of a Plume-Generated Fire Pattern (fire origin was located at the base of this damage-test conducted at EKU by author)

formed on lining materials of the compartment and contents. The damage caused by this upper layer is often times referred to as hot gas layer-generated fire patterns or heat and smoke horizons (NFPA 2014; DeHaan and Icove 2011), but in this work it will be described as upper layer-generated patterns (ULG patterns). The literature identified that investigators use the damage in two different ways. First, the upper layer-generated fire patterns are used by investigators in determining the extent to which the upper layer has descended in the compartment and that, because it is a heat source, is used to help describe other areas of damage within the compartment.

Secondly, these patterns are often used as a means to show direction of smoke and heat travel.

The ULG patterns are characterized by level lines of demarcation (or lines with similar elevation) with a generally uniform degree of damage (NFPA 2014). Noted differences with this level line of demarcation are damage in corners and near ventilation openings. Hicks et al. (2008)) noted that the lines of demarcation throughout the compartment would descend in elevation dependent on the header depth and type of opening, except the line of demarcation would descend lower in corners and ascend near ventilation openings.

The upper layer gases are elevated in temperature and have the ability to radiate heat downward onto the tops of contents throughout the compartment. Fire investigators 
describe this consistent damage to tops of contents as radiant heat damage being caused by the upper layer. Correspondingly, this heat source is often attributed to igniting contents throughout the compartment, especially those items located relatively high in elevation around the compartment (e.g. curtains). Fire investigators commonly use the lack of thermal damage behind or under contents, known as protected areas, as evidence that the damage was caused by an upper layer.

Investigators use the varying heights and direction of the lines of demarcation as indicative of directional flow. Direction of flow is typically associated with the lower line of demarcation being closer to the origin of the flow. These patterns are often witnessed on vertical surfaces of content items and wall linings. The cited basis for this pattern is the principles of fluid flow and the buoyant nature of heated gases. This is the reason that many fire investigation texts commonly refer to fire moving up and outward (DeHaan and Icove 2011; Kennedy 1959; Kennedy (1977); Kirk 1969; Rethoret 1945).

When the gases rise and expand, they begin interacting with the lining surfaces and contents in the flow of the fluid. Particulates and aerosols are deposited and heat is transferred in the same direction and flow as the smoke. As the gases rise and expand, they also begin to interact with ventilation openings. The movement of smoke from a compartment into an adjoining space is controlled by the density differences at the interface of the ventilation opening. Upper layer gases inside the compartment are driven by density differences due to their higher temperature and lower density. These gases are buoyant compared to the surrounding air at the opening interface, which causes them to flow through the opening, unless there is wind or some other external force (mechanical ventilation) allowing the pressure outside of the compartment to be higher. Therefore, the dynamic forces that drive flow through an opening are based on fluid dynamics and fluids in motion at the ventilation opening interface and the discharge characteristics of the opening. As the smoke exits the opening, it expands in volume and rises. Particulates and aerosols are commonly deposited on the wall and ceiling surface where the upper layer interacted with the lining surface (NFPA 2014). In addition, if these gases were undergoing flaming combustion as they exited the opening, thermal damage to the wall surface is expected to follow the same theory (DeHaan and Icove 2011). The resulting damage appears to be angled lines of demarcation with the lower end of the line of demarcation being nearest the source of the smoke flow (Fig. 12).

Characteristics distilled from the literature related that the ULG patterns will have level lines of demarcation with relatively uniform magnitude of damage, unless the upper layer is flowing from one location to another and,

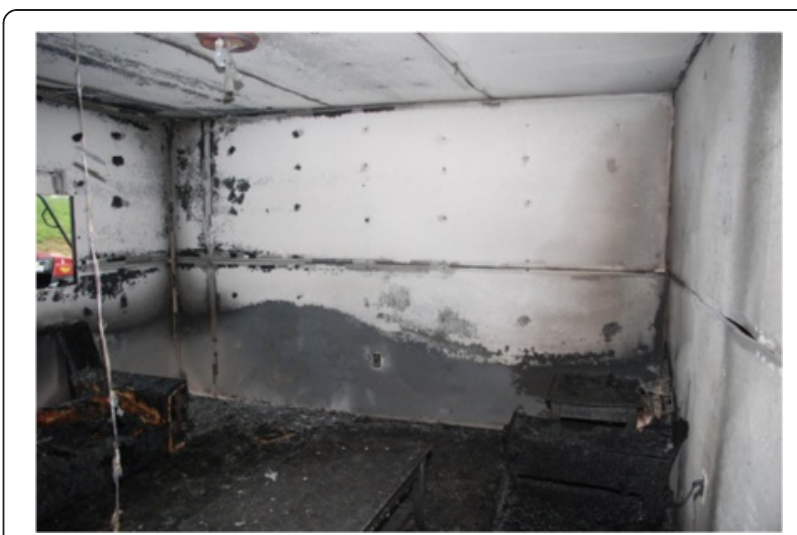

Fig. 12 Upper Layer-Generated Fire Pattern (fire origin was located along adjacent wall-fire test conducted at EKU by author)

if so, the lines of demarcation will be angled towards the opening.

Ventilation-generated fire patterns (VG Patterns)

Ventilation-generated fire patterns have been described in the literature as having a slight influence during fuelcontrolled conditions, but become the predominant issue with the location and magnitude of damage after the compartment fire is ventilation-controlled (Shanley et al. 1997; NFPA 2014; Carman 2008). First, during fuel-controlled conditions ventilation has been shown to cause the fire plume to lean away from the source of ventilation due to momentum flows from the inflow, thus influencing the truncated cone shape (Shanley et al. 1997). However, if the fire were to remain in fuelcontrolled conditions, it is not expected that this slight change in the damage from the plume would be sufficient to cause an erroneous conclusion as to the cause of the damage.

The more significant issue with ventilation-generated patterns is when the compartment fire is ventilationcontrolled. During this phase of the compartment fire, there are adequate UHCs produced, but lack sufficient oxygen for combustion. The burning during ventilationcontrolled conditions is often times detached from a fuel item (i.e. wood chair) and the pyrolyzates (unburned fuel) will burn in locations near ventilation openings and along airflow paths when sufficient oxygen for combustion exists (Custer and Wright 1984; Shanley et al. 1997; Carman 2008; Gorbett et al. 2010). Consequently, temperatures in the upper layer will also vary based on local variations in this combustion. A substantial degree of damage is often times found directly adjacent to or opposite of window and door openings. This type of damage was noted in the USFA study with specificity (Shanley et al. 1997).

Shanley et al. (1997) noted that the effect of ventilation was the one factor least understood and that ventilation- 
generated patterns were identified to be of great magnitude, sometimes greater than that of the patterns caused by the plume or origin. Their study noted that clean burn areas were observed on wall surfaces under windows that had opened during the fire and that the damage extended from the sill of the window to the floor. Also, their study noted that similar areas of great magnitude of damage occurred around doors and on walls opposite door openings.

Carman (2008) noted similar areas of damage of great magnitude directly opposite door openings and within the inflow of the air from this door. Several studies noted areas of clean burn and damage of great magnitude occurring around contents and to wall surfaces within this airflow and to wall surfaces directly opposite of the opening during ventilation-controlled conditions (Custer and Wright 1984; Shanley et al. 1997; Carman 2008; Gorbett et al. (2010)). Although, Shanley et al. (1997)) and Gorbett et al. (2010) do not find this similar effect when performing studies in compartments where the ventilation openings are connected to adjacent compartments, not directly to the exterior. Shanley et al. (1997)) reports that a damaged area of great magnitude was identified in the tests done in NIST's Large Fire Research Facility where the ventilation opening to the exterior of the compartment had access to an abundant amount of 'fresh' air. However, this area of damage was not identified in comparison studies performed in acquired structures where the opening was connected to an adjacent compartment within the house. Shanley et al. (1997)) contends that the source of available 'fresh' air from adjacent spaces will have a significant influence on whether or not the ventilation-generated patterns are prevalent with such magnitude.

Mealy et al. (2013) identified similar effects near ventilation openings in their compartment fire tests. They identified areas of damage with greater magnitude around the doorway openings. In addition, this study identified that greater damage (clean burn) occurred at the seams between drywall sections within their tests when they were not covered with tape and mud, due to leakage through the unsealed openings. This same damage near the drywall seams was identified in the Claflin study (2014) (Fig. 13).

Characteristics of the damage linked with ventilationgenerated patterns during ventilation-controlled conditions are large surface areas and increased magnitude of damage, angled lines of demarcation located around the ventilation opening or directly opposite of a door opening. Also, damage may be found near the unsealed seams of drywall sections due to infiltrating air.

Suppression generated fire patterns (SG Patterns) Suppression factors may also impact the visible and

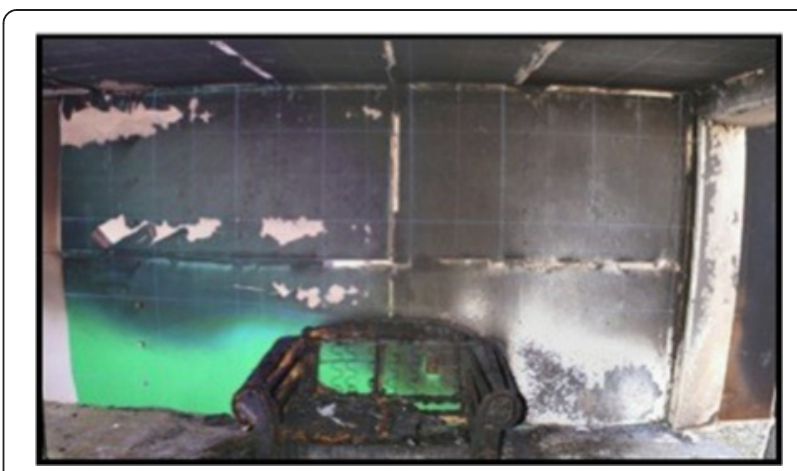

Fig. 13 Ventilation-Generated Fire Pattern near open doorway (fire origin located across room-fire test conducted at EKU by author)

measurable damage that investigators use. These factors included the location of water application, duration of fire burning prior to arrival, duration required to extinguish the fire, location of fire department entry, method of extinguishment, use of positive pressure ventilation (i.e. forced convection, mechanical movement of smoke or spreading of contaminants), the change of ventilation upon arrival (breaking windows, opening doors, cutting holes in ceiling), and overhaul after the fire has been extinguished.

No studies have been conducted specifically to evaluate these patterns, however, some characteristics of these patterns have been identified in other fire pattern studies. Shanley et al. (1997)) reported that suppressiongenerated patterns, those caused by water spray from a fire department hose line, were easily identifiable in their test series. The water spray damage was composed of many elongated streaks, less than 1-inch in length and were grouped and oriented so that they resembled a spray pattern. This study also noted that it was evident that the water did not wash all of the deposited material away from the wall or ceiling surface because "the patterns had a color which was lighter than the surrounding area but not as light as a clean burn or protected area" (Shanley et al. 1997).

Mealy et al. (2013) identified hose spray from suppression efforts as washing off areas of soot and ash from the gypsum wallboard, leaving behind a white area. These white areas were similar in appearance to clean burn patterns at first glance, but were shown upon closer examination to be differentiated based on smeared, directional appearance with observable water drip marks.

Many of the firefighting factors would not necessarily develop new patterns that have unique characteristics. For example, the location of fire department entry, the use of positive pressure ventilation and the change of ventilation upon arrival should result in fire patterns that are similar to ventilation-generated fire patterns. The only point of contention then would be the manner in 
which the ventilation opening was created. Finally, an area that is white in color surrounded by soot areas should not be classified as a clean burn area until closer examination is performed.

Alternate causal factors Andrew Cox (2013) argues that both the generic causal factors and the contextual circumstances should be considered when interpreting the cause of the damage. Cox provides an example where using these two concepts demonstrated that a white area on a wall required consideration of the causal factors and contextual circumstances to adequately evaluate the damage. He lists causal factors for this white area of damage as possibly hose stream wash, surface paper burned off leaving a 'clean' noncombustible surface behind, or the wall may have been surfaced differently prior to the fire (i.e. repairs of the drywall performed). He then indicates that the contextual circumstances should also be evaluated, which include a relationship to other artifacts and associated casual factors (proximity to a fuel item), postflashover conditions and proximity of damage to a ventilation opening. The changes to the wall surfaces by the owner through repairs and other possible information that may change the overall damage within the compartment need to be addressed.

Drywall repairs, as well as tape and mud between drywall seams or the lack of this material may alter the observations of damage in these areas and will need to be considered. Several researchers have identified significant changes in damage around drywall seams (Claflin 2014; Gorbett et al. 2010; Mealy et al. 2013). If the mud and tape were present to cover the drywall seams, then typically the damage is lesser at this area. However, if the mud and tape are not present and the compartment transitioned to a ventilation-controlled fire, the damage around these sources of ventilation may be significant (Claflin 2014; Mealy et al. 2013) (Fig. 14).

\section{Literature regarding the practice of using damage in fire investigations}

This section of the literature review focuses on the use of fire patterns and fire pattern generation to identify an area of origin. Since the beginning of fire investigations, the focus on how to determine the area of origin for a fire was to try and use damage to work backwards in an attempt to recreate the development of the fire within the investigator's mind. Many of the early texts discuss this similarly to Rethoret when he states "using the method of tracing the course of the fire and by working backwards, the actual place where the fire originated can usually be determined by the greatest damage" (Rethoret 1945). In essence this shows that fire investigators were trained to identify the greatest area of damage and that this would be the area of origin. However, even the

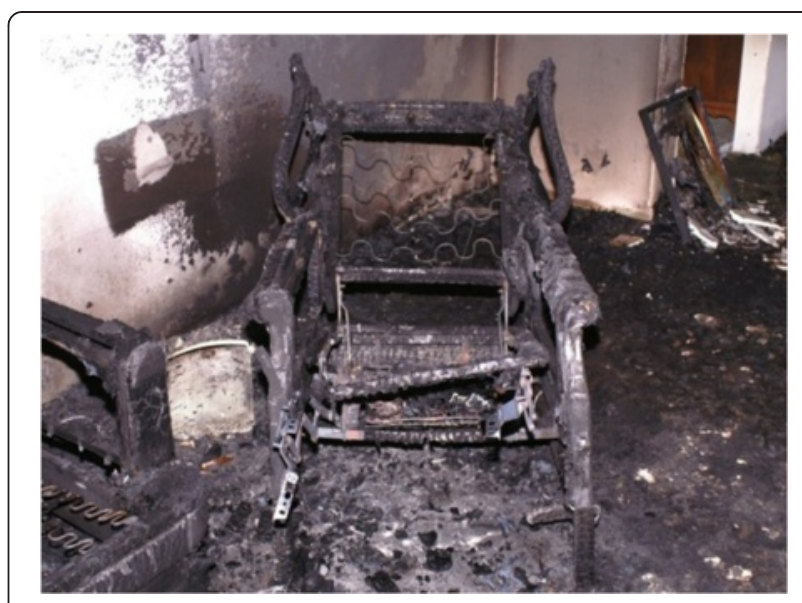

Fig. 14 Pre-fire Drywall Repairs Influencing the Post-fire Visible Damage to the Wall (fire origin located along front of chair-fire test conducted at EKU by author)

earliest text on fire investigation cautions investigators that ventilation may cause trouble with this process as it will cause greater damage in those areas of better "air currents" (Rethoret 1945). The earliest texts (Rethoret 1945; Kennedy 1959), however, do not offer a process on how to use the data, other than vague descriptions on visibly identifying greater areas of damage and tracing varying char damage.

The first identified process was published in 1955 (Straeter and Crawford 1955). The authors stated that "fire leaves its fingerprints and that each finger of flame leaves its effects and the study of these effects will help you pick the spot where it burned first" (Straeter and Crawford 1955). To accomplish this goal, the authors suggested that the area of origin could be identified through the use of damage by both (1) retracing the fire's path by the forces bearing on it and (2) retracing or reconstructing the path of the fire by the effects produced. The forces bearing on the fire were identified in this text as (a) combustibles involved, (b) openings and ventilation, (c) winds and drafts, (d) explosions and (e) variations from normal burning. The most emphasis was placed on combustibles involved and openings and ventilation.

The authors suggested that the investigator could evaluate the items involved and "the differences of flammability of combustibles along the route of travel may explain the route of travel or spread" (Straeter and Crawford 1955). They also discussed that locations and conditions of ventilation openings as functioning in "two different capacities, where the fire could pass to the next room...or it may be a source of incoming air to feed the fire" (Straeter and Crawford 1955). The second way to retrace the path of the fire towards the origin was by the use of the effects produced, which they broke down into 
evaluating six parts including (a) char, (b) remains and debris, (c) room temperatures, (d) sequence of shorted electric circuits, (e) sequence of sprinkler eruptions, (f) interiors of partitions and (g) adjoining properties.

The section on char suggested that the investigator go backward from the areas of "little char to deeper char establishing the path of fire clearly" (Straeter and Crawford 1955). They also suggested that the level of heat lines on the walls may be "traced back from the termination point toward the beginning...ordinarily they will be lower and lower on the walls as you approach the areas where the greatest heat was generated" (Straeter and Crawford 1955). This combination of using damage in the context of the fire behavior variables was new to the profession in 1955 , but then apparently lost for the next 40 years. The authors do not, however, indicate how, provided this information, an investigator arrives at a conclusion.

The next identified process was promulgated by John Kennedy in 1962 and was termed the Pointer or Arrow Theory (Kennedy 1959). The pointer theory was proffered as a "system of determining the point of origin of a fire by tracing its path back to its source...the system is based on the fact that fires normally travel by feeding on flammables. The sides exposed to the direction from which the fire is coming will be more severely burned and charred. This will leave a series of burned studs, which serve as pointers or arrows to trace the fire" (Kennedy 1959). Again, Kennedy makes the argument that the investigator needs to identify the greatest area of damage. Kennedy incorrectly makes the assumption that "in fires involving buildings or other structures where wooden joists or studding are exposed and burning, the application of the fire will usually be constant" (Kennedy 1959).

Kirk was the next to put forward a general process on how to identify the area of origin based on damage. The focus of his process was similar to the others in describing that the area of origin will be located at the greatest area of damage and the investigators should focus on identifying the low burn damage areas and using conical shapes. He encouraged investigators to focus on low burns, because as he says "any low point in a burn should be investigated as a possible origin" (Kirk 1969). However, Kirk also identifies many of the "very common complications" that can arise, which will "distract the investigator from following the fire pattern back to its point of origin" (Kirk 1969). These deviations from 'normal' patterns, as he called them, included areas of open ventilation, secondary ignition of falling material, roof or attic fires, exterior exposure fires and roof collapse. He succinctly describes his process as "direction of spread of the fire will be noted...it will be upward, partially lateral, rarely downward, but its direction will indicate the general region of origin when properly interpreted. This should and generally is, close to the low point of the burn" (Kirk 1969).

Kennedy and Kennedy (1985) described a first method as "the ' $\mathrm{V}$ ' pattern method is based on the fact that fire burns upward and outward toward available fuel, leaving a ' $V$ ' shaped pattern that can be traced back to its lowest point which would be the area of origin". The only method that appears to be systematized and examples provided was the truncated cone method in conjunction with the heat and flame vector analysis (Kennedy and Kennedy 1985). This method was used to identify each fire pattern within the compartment, ascribe a direction or intensity to that damage and assign a directional arrow on a diagram to reflect this damage, however, no specific procedural details were provided on how to implement this analysis or how to interpret direction (Kennedy and Kennedy 1985).

In 1985, Cooke and Ide put forward a process termed radius of error (Cooke and Ide 1985). Their method encouraged investigators to use fire patterns to arrive at an origin, but upon arriving at their hypothetical area(s) of origin required the investigator to provide some measure of accuracy in the form of a radius of error. Their example is as follows, "if the investigator decides he has located a seat of fire within a radius of error of $1 \mathrm{~m}$, he is certain that the original seat of fire lays within an area having one metres [sic] radius (i.e. within an area of 3.14 square metres [sic])" (Cooke and Ide 1985). Their use of this method was stated to ensure that an investigator would be required to provide an indication of the degree of accuracy, as well as provide an area for excavation. This was the first time that investigators were encouraged to assign some reliability to their origin conclusion, however, the authors failed to provide guidelines on how specifically to arrive at the initial origin hypothesis.

Since 1992, NFPA 921 has established the de facto standard of care for the fire investigation profession, yet it lacks specific procedures for origin determination (Gorbett and Chapdelaine 2014). The only procedural aspect that NFPA 921 provides for fire pattern use for origin determination is the heat and flame vector analysis (NFPA 2014). However, no specific details are provided on how to implement this analysis. The scientific method is proclaimed throughout the document as the generic process for investigating a fire, but no specific procedural details are outlined on how to implement it into practice for analyzing fire patterns.

In 1997, a formal heat and flame vector analysis was conducted with three of the USFA fire pattern tests. The results confirmed that the use of this method was appropriate for these three test fires (Shanley et al. 1997). This was the first published work that outlined how to develop a legend and diagram as demonstrative aids for applying the heat and flame vector analysis. It can be 
argued that this study was the nearest any of the methods have come to being testing for reliability or validity (Fig. 15 and Table 2).

In 2002, fire pattern analysis was identified as an essential area of research by the National Fire Protection Association's Fire Protection Research Foundation. In their report, authored by its Research Council on PostFire Investigation, they recommended, "if patterns are to be used for origin and cause determination, forensic methods to identify the specific source of a pattern need to be developed and rigorously vetted" (NFPA, 2002, p.5).

The first insistence that decision analysis should be considered for fire patterns analysis was in 2010 (Gorbett et al. 2010). The study divided the use of fire patterns into fire effects and fire dynamics attributes and called for some form of weighting of fire dynamics attributes in the overall decision process. However, the authors did not propose a working prototype.

A survey was conducted to evaluate the proficiency of professional fire investigators at determining the area of origin when provided with photographs and measurable data from a test (Tinsley and Gorbett 2013). The accuracy of the proficiency test was matched with the demographics of 586 professional fire investigators. The test fire used for this survey was setup as a residential living room furnished with a polyurethane foam couch and loveseat, end tables and a coffee table. The walls and ceiling were lined with gypsum wallboard. The fire burned for approximately two minutes post-flashover.

The participants were provided a diagram of the room and photographs of the contents, walls and ceiling. An approximate 2-square foot $\left(0.19 \mathrm{~m}^{2}\right)$ grid was established and the participants were asked to select the grid space that most represented their area of origin. Next, the

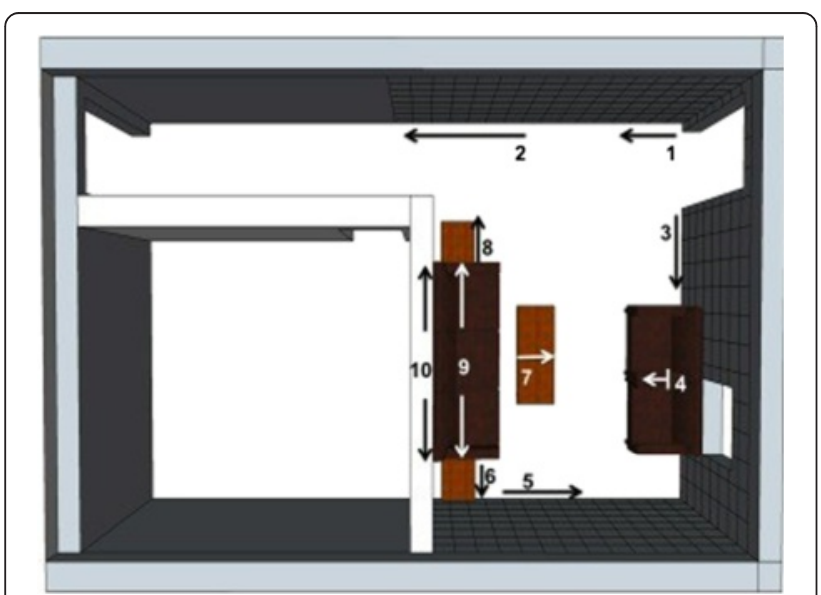

Fig. 15 Example of a Heat and Flame Vector Analysis Diagram (fire origin located in center of couch-fire test conducted at EKU by author) participants were provided with depth of char measurements for all content items and depth of calcination measurements for all of the walls for the same compartment fire and were asked to re-examine the photographs and select an area of origin again. The study concluded that $73.8 \%$ without measurable data and $77.7 \%$ with measurable data accurately determined the area of origin. Thus, the total percentage of participants choosing the correct area increased $3.9 \%$ with the inclusion of measurable data as part of the given. These results were found to be statistically significant using a chi square distribution yielding a p-value of 0.006 .

In 2013, Andrew Cox published an article proposing a new methodology for the assessment and interpretation of compartment fire damage through the use of what he termed the origin matrix (Cox 2013). Essentially this work establishes a rudimentary decision matrix that uses pre-flashover and varying durations of post-flashover as the primary consideration in identifying the location and magnitude of damage within the compartment. The central theme is that the investigator can section off a room and can use the location of ventilation openings as a predictor of the location and magnitude of damage based on the location of this ventilation and the predicted airflow from these openings.

Cox discussed the importance of separating data and the interpretation of that data when discussing this new method. He contends that damage should just be viewed as data and the investigator "must resist the temptation to interpret the meaning of individual fire effects and fire patterns in isolation" (Cox 2013). The origin matrix provides the user a diagram of the compartment of interest, where the user is to shade in those portions of the diagram where damage is identified and then this damage is to be compared to expected damage based on the predicted damage from the ventilation openings. Cox provided a process for better interpreting the compartment fire dynamics that is still under development and has not undergone a major field test for user application.

\section{Discussion}

A summary of the findings from the literature review and recommendations based on this review will be provided within this section. The literature on using fire patterns to determine an area of origin should be classified into four areas that will assist in guiding future research, including:

(1) Assessing the varying Degrees of Fire Damage (DOFD) along the surfaces of the compartment and contents (i.e. fire effects);

(2)Identifying clusters and trends of damage (i.e. fire patterns); 
Table 2 Example of a heat and flame vector analysis legend

\begin{tabular}{|c|c|c|c|}
\hline Vector & Material & Effect & Fire patterns analysis \\
\hline 1 & Gypsum wallboard & Clean burn & $\begin{array}{l}\text { Clean burn extending from doorway } 5^{\prime} \text { into compartment. Indicating intensity } \\
\text { near the doorway. }\end{array}$ \\
\hline 2 & Gypsum wallboard & Color change & $\begin{array}{l}\text { Increasing line of demarcation moving down hallway. Indicating fire travel } \\
\text { from living room down the hallway. }\end{array}$ \\
\hline 3 & Gypsum wallboard & Clean burn & $\begin{array}{l}\text { Clean burn extending from doorway to loveseat. Indicating intensity near } \\
\text { doorway. }\end{array}$ \\
\hline 4 & PU foam & Loss of mass & $\begin{array}{l}\text { Backrest cushion completely consumed, horizontal cushion still present. Near } \\
\text { uniform heat from top down, indicating a hot gas layer generated pattern. }\end{array}$ \\
\hline 5 & Gypsum wallboard & Depth of calcination & $\begin{array}{l}\text { Deeper calcination measurements in S corner of east wall. Indicating fire } \\
\text { travel from } \mathrm{S} \text { end of room towards } \mathrm{N} \text {. }\end{array}$ \\
\hline 6 & Wood & Char; depth of char & Greater visible and measurable char near sofa. Indicating fire travel from sofa. \\
\hline 7 & Wood & Char; depth of char & Greater visible and measurable char near sofa. Indicating fire travel from sofa. \\
\hline 8 & Wood & Char; depth of char & Greater visible and measurable char near sofa. Indicating fire travel from sofa. \\
\hline 9 & PU foam/wood & Loss of mass; char & Greater char and loss of mass in center of sofa. Indicating fire travel from sofa. \\
\hline 10 & Gypsum wallboard & Clean burn; depth of calcination & $\begin{array}{l}\text { Greatest area of clean burn and depth of calcination above and behind } \\
\text { center of sofa. Indicating fire travel from sofa. }\end{array}$ \\
\hline
\end{tabular}

(3)Interpreting the causal factors for the generation of the fire patterns; and,

(4) Identifying processes of using fire patterns in determining an area of origin.

\section{Assessing the varying degrees of fire damage (DOFD)-fire effects}

Many of the early and current researchers assumed that every investigator was able to visibly assess varying degrees of damage equally without processes (Shanley et al. 1997; NFPA 2014; Gorbett et al. 2010). As shown in the literature search, no system exists and therefore this assumption is unwarranted by previous researchers (Carman 2008; Tinsley and Gorbett 2013; Gorbett et al. 2014). Because the varying DOFD serves as the foundation for all later interpretations, ultimately leading to an origin determination, more research is needed to either demonstrate that investigators reliably identify varying DOFD or the industry needs processes that are shown to be reliable and valid (Gorbett and Chapdelaine 2014).

\section{Visible and measurable observations of char}

Currently, investigators have no reliable method for identifying varying DOFD for charring. One method was suggested, but was never fully conceived or put into practice (Keith and Smith 1984). This method or a similar method should be further explored using the work done for gypsum wallboard (Gorbett et al. 2014). The literature appears to identify that fire investigators can take depth measurements of char for similar types of wood to identify relative degrees of fire damage and that this may assist in identifying varying DOFD, but they should not assign duration of exposure to those measurements unless the conditions of the samples can meet those specifically expressed in Babrauskas's (2005) work.

\section{Visible and measurable observations of calcination}

A visible degree of fire damage scale (DOFD) was developed for gypsum wallboard and was shown to decrease variability in novices ranking varying degrees of fire damage across a wall surface (Gorbett et al. 2014). More work is required to further examine these results. Several studies have shown that the depth of calcination reliably indicates intensity and duration of heat exposure. A standardized depth tool needs to be implemented to decrease error, similar to the one developed by Barnott et al. (2013). A new method of using digital image analysis may also work in increasing the objectivity of identifying varying DOFD (Riahi et al. 2013). Most of the studies conducted on calcination are limited in their examination of gypsum wallboard variations. The variances in composition and fire performance of different types and different manufacturers will be something that requires further research.

\section{Identifying fire patterns}

No literature exists that defines methods on how to identify a fire pattern from a cluster of damage. It is important for reliability and validity that the industry develop processes to assist investigators to objectively identify fire patterns.

The current definition for fire patterns is "the visible or measurable physical changes, or identifiable shapes, formed by a fire effect or group of fire effects" (NFPA 2014). This definition is insufficient compared to how the profession currently uses the term. A better definition is warranted for this term. 
As the definition from the term fire pattern has evolved and will continue to evolve, it is important to define what a pattern is first. The most common definition of a pattern is "something that happens in a regular and repeated way, combination of qualities forming consistent or characteristic arrangement and frequent or widespread incidence" (Pattern 2015). The fundamental items within the definition that may assist in better defining the term fire pattern is that patterns are something that happens in regular and repeated ways with characteristic features.

Combining the definition of pattern with the current definition of fire patterns provides a better definition. The proposed definition for fire patterns is

"a distinct area of damage or cluster of fire effects with identifiable and related lines of demarcation that share common damage characteristics, such as type, magnitude, direction and proximity (e.g. location and elevation)".

The elements of the fire pattern definition are further explained here:

1. "distinct area of damage or cluster of fire effects" the area of damage must be clearly distinguishable from other areas of damage through the identification of line(s) of demarcation. Other areas of damage can surround the pattern, but the pattern must have characteristics that allow the limits of it to be individually identified.

2. "identifiable and related lines of demarcation" - it is important that the lines of demarcation are objectively verifiable by all experts and that a pattern is something that can be objectively identified without interpretation. The related lines of demarcation are ensuring that the area being called a pattern have associated boundaries or lines of demarcation. The term 'related' also is included to permit the linkage of the lines of demarcation with progressively increasing or decreasing degrees of damage, such as flow of a hot gas into/out of a compartment.

3. "share common damage characteristics" - for the damage to transition from simply random areas of damage to being classified as a pattern requires that the damages are clustered near to each other and that the characteristics of the damage are similar.

4. The characteristics that are proposed here include the "type, magnitude, direction and proximity (e.g. location and elevation)". Magnitude refers to the degree of damage to the material. A pattern requires that the degree of damage between varying materials and along the same material reflect a similar intensity/duration of exposure to the byproducts of combustion. As mentioned before, if the magnitude of damage is changing, but the lines of demarcation are related, then a pattern may still exist. A pattern may encompass the varying DOFD areas as long as the line of demarcation are linked by direction. Proximity requires that the varying fire effects be within the same vicinity to each other. Location and elevation are essentially further describing proximity. Finally, 'type of damage' indicates the physical or chemical changes to the material, such as penetration, flaking, deposition, consumption and other material decomposition fire effects.

Processes that identify thresholds needed for fire patterns to be identified can be better defined through experimental work or pattern recognition studies.

\section{Fire pattern generation}

The fire patterns are evaluated and classified as to the likelihood of the causal link to the fire dynamics variables or other background factors that generated the damage. NFPA (2014) refers to this as fire pattern generation and provides a list of them including plume-generated, ventilationgenerated, hot gas layer-generated and suppressiongenerated. Attributing a fundamental interpretation to an observation, specifically one that ties the underlying physics to an observation, is a major key to accurately determining the true fire scenario and area of origin. Ultimately, the locations of damage and fire patterns are compared to the causal factors from the physics of the fire, alternative causes and background information.

\section{Plume-generated (PG) fire patterns}

The characteristics distilled from the literature are that plume-generated patterns have areas of greater magnitude of damage in relation to the surrounding areas and because of this, the lines of demarcation between these areas are described as clear or sharp. Also, the lines of demarcation are not parallel to the floor, but are at an angle representing the buoyant flow, usually with characteristic geometric shapes. The fire pattern studies revealed that specific damage cues identified during fuel-controlled conditions were not as prevalent during ventilation-controlled conditions.

The damage cues evaluated for plume-generated damage included:

- Cue 1-loss of mass to fuel is consistent with damage to affected surface.

- Cue 2-increased magnitude of damage near the fuel item.

- Cue 3-elevation of the line of demarcation is consistent with the height of the fuel item. 
- Cue 4-width of base of damage is approximately the width of the fuel item and not greater than two times the width of the fuel item.

- Cue 5-lines of demarcation are angled emanating from the fuel item.

- Cue 6-sharp/distinct lines of demarcation near or appear to be emanating from the fuel item.

- Cue 7-conical shape.

The following statistics were accumulated while performing the literature review and summarized here for PG fire patterns. The statistics can be found in the Excel Spreadsheet associated with this review paper. The fuelcontrolled conditions had consistently higher probabilities in positively identifying each cue as compared to ventilation-controlled conditions. In fuel-controlled conditions, cues 2-4 were positively identified in $92 \%$ of the studies $(23 / 25)$, cues 1 and 5 were positively identified in $88 \%$ of the studies $(22 / 25)$, cue 6 was positively identified in $84 \%$ of the studies $(21 / 25)$, and cue 7 was identified in only $68 \%$ of the studies $(17 / 25)$. In ventilation-controlled conditions, cue 1 was the most positively identified in $87 \%$ of the studies (39/45), cues $2-5$ were identified in $76 \%$ of the studies $(34 / 45)$, cue 6 was identified in $62 \%$ of the studies $(28 / 45)$, and cue 7 was only identified in $42 \%$ of the studies $(19 / 45)$.

\section{Upper layer-generated (ULG) fire patterns}

The characteristics distilled from the literature are that the ULG patterns will have level lines of demarcation with relatively uniform magnitude of damage, unless the upper layer is flowing out of a compartment and if so the lines of demarcation will be angled towards the opening.

The fire pattern studies revealed that the upper layer damage is very difficult to identify after the fire has transitioned into ventilation-controlled conditions. The presence of a soffit and the size of an opening influences the depth of the damage within the compartment, however, as the compartment nears flashover damage begins to occur at lower elevations on all surfaces. This damage begins to obscure some of the earlier lines of demarcation from the upper layer. The damage cues evaluated for upper layer-generated damage included:

- Cue 1-damage high in elevation on wall surfaces.

- Cue 2-uniform magnitude of damage.

- Cue 3-increasing lines of demarcation moving out of vent openings.

- Cue 4- level lines of demarcation along all wall surfaces.

The following statistics were accumulated while performing the literature review and summarized here for
ULG fire patterns. The statistics can be found in Additional file 1 associated with this review paper. The ventilation-controlled conditions did not result in any upper layer damage that was discernable, therefore it will not be considered here. In fuel-controlled conditions, cues 1 and 2 were the most positively identified in $80 \%$ of the studies $(20 / 25)$, cue 3 was identified in $60 \%$ of the studies $(15 / 25)$, and cue 4 was only identified in $48 \%$ of the studies $(12 / 25)$. Given these findings, damage cues 1, 2 and 3 are used as the most accurate damage cues for classifying a fire pattern generated by upper layer.

\section{Ventilation-generated (VG) fire patterns}

Characteristics of the damage linked with ventilationgenerated patterns during ventilation-controlled conditions are large surface areas of damage, increased magnitude of damage, damage found near unsealed drywall seams and angled lines of demarcation located around the ventilation opening or directly opposite of a door opening.

The fire pattern studies revealed that ventilation rarely causes any damage of significance during fuel-controlled conditions. However, ventilation becomes one of the more prominent influences of damage when the compartment has transitioned into ventilation-controlled conditions. The presence of a ventilation opening is necessary. Door openings to the exterior were identified as being the most influential to damage. The damage cues evaluated for ventilation-generated damage included:

- Cue 1-increased area and magnitude of damage within the airflow from the opening.

- Cue 2-increased area and magnitude of damage across from the opening.

- Cue 3-increased magnitude of damage around opening within 2 times the opening width $\left(2 \mathrm{w}_{\mathrm{v}}\right)$.

- Cue 4-lines of demarcation are angled emanating from the ventilation opening.

- Cue 5-increased area and magnitude of damage under the window.

- Cue 6-increased area and magnitude of damage around gypsum wallboard seams.

The following statistics were accumulated while performing the literature review and summarized here for VG fire patterns. The statistics can be found in Additional file 1 associated with this review paper. The fuel-controlled conditions did not have any damage associated with ventilation openings, therefore it will not be considered here. In ventilation-controlled conditions, cue 1 was the most positively identified in $82 \%$ of the studies (37/45), cue 2 was identified in $73 \%$ of the studies (33/45), cue 4 was identified in $64 \%$ of the studies $(29 / 45)$, cue 6 was identified in $62 \%$ of the studies (28/45), cue 3 was identified in $53 \%$ of 
the studies (24/45), and cue 5 was only identified in $11 \%$ of the studies. Given these findings, damage cues 1, 2 and 4 are used as the most accurate damage cues for classifying a fire pattern generated by ventilation.

\section{Suppression-generated (SG) fire patterns}

Many of the suppression factors would not necessarily develop new patterns that have unique characteristics. For example, the location of fire department entry, the use of positive pressure ventilation and the change of ventilation upon arrival should result in fire patterns that are similar to ventilation-generated fire patterns. The only point of contention then would be the manner and reason in which the ventilation opening was created. Finally, an area that is white in color surrounded by soot areas should not be classified as a clean burn area until closer examination is performed.

\section{Identifying processes of using fire patterns in determining an area of origin}

In the face of non-systematized approaches to solving complex problems, the current state of fire investigation, many other professions have turned to decision support frameworks, tools or methods. As used here, decision frameworks, tools or methods encompass any mechanism used to support the systematic identification and assessment of information deemed important to a decision, ranging from checklists to structured problemdiagnostic tools such as fault trees, event trees or decision trees, to computationally supported decision analysis tools. Decision support frameworks are derived from the field of decision analysis, as well as from uncertainty analysis and risk analysis.

Decision analysis has its roots in operations research, where it emerged from a desire to better understand and address decision-making under uncertainty, becoming viewed as a unique area of study in the 1960s (Howard 1966; Raiffa 1968). A fundamental principle of decision analysis is that people do not always have all the data or information needed to make a good decision. In addition, they may not know where or how to obtain additional information, or how to judge the value of the information in the context of the overall decision. As these problems began to be studied, approaches were developed to help individuals and organizations identify the components of a good decision, how to structure the decision problem and how to treat the associated uncertainty (Clemen and Reilly 2001; Donegan 2008; Kahneman and Tversky 1974; Kleindorfer et al. 1993; Morgan and Henrion 1990; Von Winterfeldt and Edwards 1986).

Key aspects of a decision support framework include identification of decision objectives, attributes (criteria) which are important to the decision problem and the weighting (importance) of the attributes to the decision given the uncertainty and variability in the data and relationship between the attributes. Once these parameters are identified and organized, various techniques can be applied to facilitate the collection of critical information, analysis of the data and facilitation of a decision.

IThis type of structured approach to reaching better decisions has been applied in various fields, from business and economic decisions (Clemen and Reilly 2001), to building and fire safety analysis and regulation (Donegan 2008; Meacham 2000), diagnostic support within the psychological, psychiatric and medical professions (Boorse 1976; DSM-IV-TR 2000), failure analysis (Benner 1975; Ericson 1999; Vesely et al. 2002) and forensic analysis (Taroni et al. 2005; Morvan et al. 2007; Jarman et al. 2008), including with respect to fire investigation (Biedermann et al. 2004).

\section{Conclusions}

The literature review of fire pattern usage in the fire investigation profession illustrates several gaps with the overall process of using damage to determine an area of origin. First, a poor assumption by many of the fire investigation guides, textbooks and research was that every investigator is able to visibly assess varying DOFD equally (Shanley et al. 1997; NFPA 2014; Gorbett et al. 2010). However, this has not been demonstrated through proficiency testing done to determine the area of origin based on visible observations (Carman 2008; Tinsley and Gorbett 2013). Several recent studies have provided processes to assist in the objective identification of the varying degrees of damage, including a degree of fire damage scale for visible damage (Gorbett et al. 2013), a standardized depth measurement system (Mealy et al. 2013), and the use of digital image analysis (Riahi et al. 2013). More validity and reliability studies are required for these methods.

Currently, no systematic method exists for fire investigators to identify a fire pattern. Developing a process for the objective identification of areas requiring further attention during fire investigation that is universally accepted by the community is recommended to increase the reliability and accuracy of fire origin determinations.

The only process for fire pattern analysis discussed in the literature is the use of a heat and flame vector analysis (NFPA 2014; Shanley et al. 1997). Many of the studies contend that this process assists investigators in determining the correct area of origin (Shanley et al. 1997; Gorbett et al. 2010). However, no formal procedure has been developed, including: how to determine a direction, how to incorporate compartment fire dynamics into the process and how to make an area of origin conclusion based on the results. Furthermore, this process has not been widely tested for reliability or validity. 
When lacking a systematic approach to solving complex problems, many professions have turned to decision support frameworks, tools or methods, the intent of which are to guide the decision by asking questions and helping to assess the weight or importance of variables. It is suggested from this literature review that the overall reasoning process for evaluating fire damage for determining an area of origin consists of the following seven steps (Gorbett 2015):

(1)Identifying the value in further analysis of a surface or compartment;

(2)Identification of the varying degrees of fire damage (DOFD) along the surfaces of the compartment and contents;

(3)Identifying clusters and trends of damage (fire patterns);

(4) Interpreting the causal factors for the generation of the fire patterns;

(5)Developing area(s) of origin hypotheses;

(6) Testing the hypothetical area(s) of origin; and,

(7) Selecting a final area of origin hypothesis.

Each of the seven steps will have a process or multiple processes that assist in moving the decision maker through the overall process of determining an area of origin. The profession requires new research to span the gaps identified within each sub process. All processes used for origin determination should undergo reliability and validity testing (Gorbett 2015). Standardized proficiency testing should be developed for each process developed and all users of these processes should be tested for proficiency.

\section{Endnote}

${ }^{1}$ Of course, apex is actually the antonym of the word desired here. The correct word is nadir, but to remain consistent with these texts apex will be used.

\section{Additional file}

Additional file 1: Test Data from Published Full-Scale Fire Pattern Tests and Statistics for Fire Pattern Generation.

\section{Competing interests}

The authors declare that they have no competing interests.

\section{Authors' contributions}

All authors read and approved the final manuscript.

\section{Acknowledgements}

The authors would like to thank Bill Hicks for providing pictures taken during fire testing.

\section{Author details}

${ }^{1}$ Department of Fire Protection Engineering, Worcester Polytechnic Institute, 100 Institute Road, Worcester, MA 01609, USA. ²Department of Fire
Protection and Paramedicine Sciences, Fire, Arson and Explosion Investigation Program, Eastern Kentucky University, 521 Lancaster Avenue, Richmond, KY 40475, USA. ${ }^{3}$ FireLink, LLC, 1501 Main Street, Suite 17, Tewksbury, MA 01876, USA.

Received: 1 February 2015 Accepted: 19 May 2015

Published online: 28 May 2015

\section{References}

Abib A, Jaluria Y (1992a) Turbulent penetrative and recirculating flow in a compartment fire. American Society of Mechanical Engineers, Heat and Mass Transfer in Fire and Combustion Systems, HTD 223:11-19

Abib A, Jaluria Y (1992b) Penetrative convection in a partially open enclosure. American Society of Mechanical Engineers, Natural Convection in Enclosures, HTD 192:73-81

Babrauskas V (1980) Estimating room flashover potential. Fire Technology 16(2):95-103

Babrauskas V (1981) Will the second item ignite? Fire Safety Journal 4:281-292

Babrauskas V (2005) Charring rate of wood as a tool for fire investigations. Fire Safety Journal 40:528-554

Barnott A, Hardman R, Hoff N (2013) An Improved Method for Measuring Depth of Calcination in Fire Investigations. Poster presented at the International Association of Arson Investigators Annual Training Conference, Florida (USA) Barracato J (1979) Fire... is it arson? Aetna Life and Casualty, Connecticut (USA)

Battle B, Weston P (1960) Arson: A Handbook of Detection and Investigation. Arco Publishing Company, New York (USA)

Benner L (1975) Accident Theory and Accident Investigation. Proceedings of the Society of Air Safety Investigators Annual Seminar

Beyler C (1986) Fire plumes and ceiling jets. Fire Safety Journal 11:53-75, London (UK)

Beyler C (2009) Analysis of the Fire Investigation Methods and Procedures Used in the Criminal Arson Cases Against Ernest Ray Willis and Cameron Todd Willingham. Hughes Associates, Maryland (USA)

Bieber P (2014) Anatomy of Wrongful Arson Conviction: Sentinel Event Analysis in Fire Investigations. Paper presented at the International Symposium on Fire Investigations. Investigations Institute, Florida (USA)

Biedermann A, Taroni F, Delemont O, Semadeni C, Davison A (2004) The evaluation of evidence in the forensic investigation of fire incidents (Part l): an approach using Bayesian networks. Forensic Science International 147:49-57

Boudreau J, Kwan Q, Faragher W, Denault G (1977) Arson and Arson Investigation-Survey and Assessment. Law Enforcement Assistance Administration. United States Department of Justice, Washington, D.C. (USA)

Brannigan F, Bright R, Jason N (1980) Fire Investigation Handbook. National Bureau of Standards, U.S. Department of Commerce, Washington, D.C. (USA)

Carman S (2008) Burn Pattern Development in Post-Flashover Fires. Paper presented at the International Symposium on Fire Investigations. Investigations Institute, Florida (USA)

Carman S (2010) "Clean Burn" Fire Patterns - A New Perspective for Investigators. Paper presented at the International Symposium on Fire Investigations. Investigations Institute, Florida (USA)

Claflin P (2014) Effects of Multiple Ventilation Openings on a Post-Flashover Compartment Fire. Fire and Arson Investigator Journal of the International Association of Arson Investigators 64(3):16-25

Clemen R, Reilly T (2001) Making Hard Decisions. Duxbury, California (USA)

Cooke R, Ide R (1985) Principles of Fire Investigation. The Institution of Fire Engineers, Leicester (UK)

Cox A (2013) Origin Matrix Analysis: A Systematic Methodology for the Assessment and Interpretation of Compartment Fire Damage. Fire and Arson Investigator Journal of the International Association of Arson Investigators 64(1):37-47

Custer R, Wright C (1984) Open Windows and Thermal Inversions may Complicate a Fire Investigation. Fire and Arson Investigator Journal of the International Association of Arson Investigators 6:89-91, Crofton, MD

DeHaan J (1983) Kirk's Fire Investigation. Pearson, New Jersey (USA)

DeHaan J (1987) Are Localized Burns Proof of Flammable Liquid Accelerants? Fire and Arson Investigator Journal of the International Association of Arson Investigators 19:127-133, Crofton, MD

DeHaan J, Icove D (2011) Kirk's Fire Investigation. Pearson/Brady, New Jersey (USA)

Delichatsios M (1984) Flame Heights of Turbulent Wall Fire with Significant Flame Radiation. Combustion Science and Technology 39:195-214 
Dillon S (1998) Analysis of the ISO 9705 Room/Corner Test: Simulations, Correlations and Heat Flux Measurements. National Institute of Standards and Technology, NIST-GCR-98-756, Gaithersburg, MD

Donegan H (2008) Decision Analysis. Section 5, Ch. 2, SFPE Handbook of Fire Protection Engineering, 4th edn. NFPA, Quincy, MA

Drysdale D (2011) An Introduction to Fire Dynamics, 3rd edn. Wiley, Chichester (UK)

DSM-IV-TR (2000) Diagnostic and Statistical Manual of Mental Disorders. In: Text Revision, Fourthth edn. American Psychiatric Association, Washington, DC

Eaton T (1987) Underfloor Fires. Fire and Arson Investigator Journal of the International Association of Arson Investigators 19:115-118, Crofton, MD

Ericson C (1999) Fault Tree Analysis - A History. Proceedings of the 17th International Systems Safety Conference, Unionville, VA

Ettling B (1990) The Significance of Alligatoring of Wood Char. Fire and Arson Investigator Journal of the International Association of Arson Investigators 32:81-84, Crofton, MD

Fitch R, Porter E (1968) Accidental or Incendiary. Charles C. Thomas Publisher, Illinois (USA)

Francis J, Chen A (2012) Observable characteristics of flashover. Fire Safety Journal 51:42-52

Gorbett G (2015) Development and Assessment of a Decision Support Framework for Enhancing the Forensic Analysis and Interpretation of Fire Patterns. Dissertation, Worcester Polytechnic Institute

Gorbett G, Chapdelaine W (2014) Scientific Method - Use, Application and Gap Analysis for Origin Determination. Plenary Paper Presented at the International Symposium on Fire Investigations. Investigations Institute, Florida (USA)

Gorbett G, Hicks W, Kennedy P, Hopkins R (2006) Full-Scale Room Burn Pattern Study. Paper presented at the International Symposium on Fire Investigations. Investigations Institute, Florida (USA)

Gorbett G, Hicks W, Tinsley A, Kennedy P (2010a) Fire Patterns with Low Heat Release Rate Initial Fuels. Paper presented at the International Symposium on Fire Investigations. Investigations Institute, Florida (USA)

Gorbett G, Meacham B, Wood C (2010b) Development and Assessment of a Decision Support Framework for Enhancing the Forensic Analysis and Interpretation of Fire Patterns. Plenary Paper presented at the International Symposium on Fire Investigations. Investigations Institute, Florida (USA)

Gorbett G, Hicks W, Tinsley A (2013) Fire patterns with low heat release rate initial fuels. Fire and Arson Investigator Journal of the International Association of Arson Investigators 64:18-33

Gorbett G, Morris S, Meacham B, Wood C (2014) A new method for the characterization of the degree of fire damage to gypsum wallboard for use in fire investigations. J of Forensic Sci. doi:10.1111/1556-4029.12616

Gottuk D (1992) The Generation of Carbon Monoxide in Compartment Fires. Dissertation, Virginia Polytechnic Institute and State University

Gottuk D, White D (2008) Liquid Fuel Fires. SFPE Handbook of Fire Protection Engineering. National Fire Protection Association, Massachusetts (USA)

Harmathy T (1972) A new look at compartment fires, part I and part II. Fire Technology 8(3):196-217

Harmer R, Nolan T, Moss R, Thaman R (1983) Liquid Burn Patterns on Linoleum. Fire and Arson Investigator Journal of the International Association of Arson Investigators 2:80-82, Crofton, MD

Heskestad G (1982) Engineering relations for fire plumes. Society of Fire Protection Engineers, Technology Report 82-8

Heskestad G (2008) Fire Plumes, Flame Height and Air Entrainment. Section 2, Ch. 1, 4th edn. SFPE Handbook of Fire Protection Engineers, NFPA, Quincy, MA

Hicks W, Gorbett G, Kennedy P, Hopkins R, Abney W (2006) Advanced Fire Pattern Research Project. Paper presented at the International Symposium on Fire Investigations. Investigations Institute, Florida (USA)

Hicks W, Gorbett G, Hopkins M, Kennedy P, Hopkins R, Thurman T (2008) Full-Scale Single Fuel Package Fire Pattern Study. Paper presented at the International Symposium on Fire Investigations. Investigations Institute, Florida (USA)

Hoffmann J, Hoffman D, Kroll E, Kroll M (2003) Full Scale Tests of Television Sets and Electronic Appliances. Fire Technology 39:207-224

Hopkins R, Gorbett G, Kennedy P (2007) Fire Pattern Persistence Through Post-Flashover Compartment Fires. Paper presented at the Fire and Materials Conference. Interscience Communications, London (UK)

Hopkins R, Gorbett G, Kennedy P (2008) Fire Pattern Persistence Through Post-Flashover Compartment Fires. Paper presented at the International Symposium on Fire Investigations. Investigations Institute, Florida (USA)
Hopkins R, Gorbett G, Kennedy P (2009) Fire Pattern Persistence Through Post-Flashover Compartment Fires. Paper presented at the Fire and Materials Conference. Interscience Communications, London (UK)

Houck M, Siegel J (2006) Fundamentals of Forensic Science. Elsevier, Massachusetts (USA)

Howard R (1966) Decision Analysis: Applied Decision Theory. In: Proceedings of the Fourth International Conference on Operations Research. John Wiley \& Sons, New York, NY, pp 55-71

Jahn W, Rein G, Torero J (2008) The effect of model parameters on the simulation of fire dynamics. Fire Safety Science 9:1341-1352

Jarman K, Kreuzer-Martin H, Wunschel D, Valentine N, Cliff J, Petersen C, Colburn H, Wahl K (2008) Bayesian-integrated microbial forensics. Appl Environ Microbiol 74(11):3573-3582. doi:10.1128/AEM.02526-07

Jowsey A (2007) Fire Imposed Heat Fluxes for Structural Analysis. Dissertation, The University of Edinburgh

Kahneman D, Tversky A (1974) Judgment under uncertainty: heuristics and biases. Science 185:1124-1131

Kawagoe K (1958) Fire Behavior in Rooms. Building Research Institute of Japan., p 27

Keith, Smith (1984) Analysis of Char Patterns Known as "Alligatoring". International Association of Arson Investigators 5:119-120, Crofton, MD

Kennedy J (1959) Fire and Arson Investigating. Investigations Institute, Illinois (USA)

Kennedy J (1977) Fire, Arson and Explosion Investigation. Investigation Institute, Illinois (USA)

Kennedy, Kennedy (1985) Fire, Arson and Explosion Investigation. Investigation Institute, Illinois (USA)

Kennedy P, Hopkins R, Kennedy K (2003) Depth of Calcination Measurement in Fire Origin Analysis. Paper presented at the 8th International Conference, Fire and Materials 2003. Interscience Communications, London (UK)

Kerber S (2010) Impact of Ventilation on Fire Behavior in Legacy and Contemporary Residential Construction. Underwriters Laboratories, Illinois (USA)

Kerber S, Walton W (2005) Effect of Positive Pressure Ventilation on a Room Fire. National Institute of Standards and Technology, NIST Technical Note 7213, Maryland (USA)

King C (1985) Ethics and Arson Investigation. Fire and Arson Investigator Journal of the International Association of Arson Investigators 11:15-18, Crofton, MD

Kirk P (1969) Fire Investigation. Wiley, California (USA)

Kleindorfer P, Kunreuther H, Schoemaker P (1993) Decision Sciences: An Integrative Perspective. Cambridge University Press, New York (USA)

Lattimer B (2008) Heat Fluxes from Fires to Surfaces. Section 2, Ch. 14, 4th edn. SFPE Handbook of Fire Protection Engineers, NFPA, Quincy, MA

Lattimer B, Sorathia H (2003) Thermal characteristics of fires in a noncombustible corner. Fire Safety Journal 38:709-745

Lentini J (2012) Scientific Protocols for Fire Investigation. CRC Press, Boca Raton (USA)

Madrzykowski D, Fleischmann C (2012) Fire Pattern Repeatability: A Study in Repeatability. Journal of Testing and Evaluation 40. doi:10.1520/JTE104261

Madrzykowski D, Kerber S (2009) Fire Fighting Tactics under Wind Driven Conditions: Laboratory Experiments. National Institute of Standards and Technology, NIST Technical Note 1618, Maryland (USA)

Mann D, Putaansuu N (2009) Studies of the Dehydration/Calcination of Gypsum Wallboard. Paper presented at the Fire and Materials 2009 Conference. Interscience Communications, London (UK)

Mann, Putaansuu (2010) Studies of the Dehydration/Calcination of Gypsum Wall Board. International Association of Arson Investigators 61:38-44, Crofton, MD

McCaffrey B, Quintiere J (1977) Buoyancy-driven counter-current flows generated by a fire source. Heat Transfer and Turbulent Buoyant Convection 2:457-472

McCaffrey B, Quintiere J, Harkleroad M (1981) Estimating room temperature and likelihood of flashover using fire test data correlation. Fire Technology 17(2):98-119

McGraw R, Mowrer F (1999) Flammability of Painted Gypsum Wallboard Subjected to Fire Heat Fluxes. Paper presented at InterFlam'99. Interscience Communications, London (UK)

Meacham B (2000) Application of a Decision-Support Tool for Comparing and Ranking Risk Factors for Incorporation into Performance-Based Building Regulations. Proceedings of The 3rd International Conference on PerformanceBased Codes and Fire Safety Design Methods, SFPE, Bethesda, MD (USA)

Mealy C (2013) Ignitable Liquid Fuel Fires in Buildings - A Study of Fire Dynamics. Grant No. 2009-DN-BX-K232. Department of Justice, USA 
Mealy C, Gottuk D (2012) A Study of Calcination of Gypsum Wallboard. Paper presented at the International Symposium on Fire Investigations. Investigations Institute, Florida (USA)

Mealy C, Wolfe A, Gottuk D (2013) Forensic Analysis of Ignitable Liquid Fuel Fires in Buildings. Grant No. 2009-DN-BX-K232. Department of Justice, USA

Milke J, Hill S (1997) Full-scale room fire experiments conducted at the University of Maryland. National Institute of Standards and Technology, NIST GCR-96-703, Gaithersburg, MD

Minnich T (2000) Results of TWGFEX Scene Survey., http://ncfs.ucf.edu/twgfex/ docs/Scene_Survey_Results.pdf. Accessed January 1, 2015

Morgan M, Henrion M (1990) Uncertainty: A Guide to Dealing with Uncertainty in Quantitative Risk and Policy Analysis. Cambridge Press, Cambridge (UK)

Morvan G, Jolly D, Dupont D, Kubiak P (2007) A Decision Support System for Forensic Entomology., Paper presented at EUROSIM 2007 conference, http://www.forenseek.org/spip/?A-Decision-Support-System-for,46

NFPA (1992) NFPA 921-Guide for Fire and Explosion Investigation. National Fire Protection Association, Quincy (USA)

NFPA (2001) NFPA 921-Guide for Fire and Explosion Investigation. National Fire Protection Association, Quincy (USA)

NFPA (2002) Recommendations of the Research Advisory Council on Post-fire Analysis - A White Paper. Fire Protection Research Foundation, Quincy, MA

NFPA (2004) NFPA 921-Guide for Fire and Explosion Investigation. National Fire Protection Association, Quincy (USA)

NFPA (2008) NFPA 921-Guide for Fire and Explosion Investigation. National Fire Protection Association, Quincy (USA)

NFPA (2014) NFPA 921-Guide for Fire and Explosion Investigations. National Fire Protection Association, Quincy (USA)

Ngu C (2004) Calcination of Gypsum Plasterboard under Fire Exposure. Dissertation, University of Canterbury

NIJ (2009) Strengthening Forensic Science in the United States: A Path Forward. National Research Council, Washington, D.C. (USA)

Oullette J (2008) ATF FRL Fire Test Report 3589, 3593, 3595. ATF, Ammendale, $M D$

Pattern (2015) Merriam Webster Dictionary. Encyclopedia Britannica Company, Chicago, www.Merriam-webster.com/dictionary/pattern

Pitts W (1994) The Global Equivalence Ratio Concept and the Prediction of Carbon Monoxide Formation in Enclosure Fires. National Institute of Standards and Technology, NIST Monograph 179, Gaithersburg, MD

Posey E, Posey J (1983) Using Calcination of Gypsum Wallboard to Reveal Burn Patterns. Fire and Arson Investigator Journal of the International Association of Arson Investigators 1:25-26, Crofton, MD

Putorti A (1997) Full Scale Room Burn Pattern Study. National Institute of Justice, Report 601-97, Washington D.C. (USA)

Putorti A (2001) Flammable and Combustible Liquid Spill/Burn Pattern. National Institute of Justice, Report 604-00, Washington D.C. (USA)

Qian C, Saito K (1992) Fire-Induced Flow Along the Vertical Corner Wall. First Asian Conference on Fire Science and Technology, China

Quintiere J (1995) Compartment Fire Modeling. Chapter 3, SFPE Handbook of Fire Protection Engineering. NFPA, Quincy, MA, pp 3.125-3.133

Quintiere J, McCaffrey B (1980) The Burning of Wood and Plastic Cribs in an Enclosure. Volume I, National Bureau of Standards, NBSIR 80-2054, Gaithersburg, MD

Raiffa H (1968) Decision Analysis. Addison-Wesley, Reading, MA

Rethoret H (1945) Fire Investigations. Recording and Statistical Corporation, Canada

Riahi S (2012) Development of Tools for Smoke Residue and Deposition Analysis. NIJ Grant No. 2007-DN-BX-K236. Department of Justice, USA

Riahi S, Beyler C (2011) Measurement and Prediction of Smoke Deposition from a Fire Against a Wall. Fire Safety Science 10:641-654

Riahi S, Beyler C, Hartman J (2013) Wall smoke deposition from a hot smoke layer. Fire Technology 49:395-409

Saito K (1993) Study of Fire Induced Flow Along the Vertical Corner Wall. National Institute of Standards and Technology, Grant 60NAN81D1142, Gaithersburg, MD

Schroeder R (1999) Post-Fire Analysis of Construction Materials. Dissertation, University of California, Berkeley

SFPE (1999) Assessment of Flame Radiation to External Targets from Pool Fires. Engineering Guide, Society of Fire Protection Engineers, Maryland (USA)

Shanley J, Alletto W, Corry R, Herndon J, Kennedy P, Ward J (1997) The United States Fire Administration (USFA) Program for the Study of Fire Patterns. Federal Emergency Management Agency, Washington D.C. (USA)
Smith F (1983) Gasoline Detection in Hardwood Parquet Flooring Six Days After Total Burnout. Fire and Arson Investigator Journal of the International Association of Arson Investigators 4:55-58, Crofton, MD

Steckler K, Quintiere J, Rinkinen W (1982) Flow Induced by Fire in a Compartment. National Bureau of Standards, NBSIR 82-2520, Maryland (USA)

Stickney (1984) Recognizing Where Arson Exists. Fire and Arson Investigator Journal of the International Association of Arson Investigators 7:16-18, Crofton, MD

Straeter R, Crawford C (1955) Techniques of Arson Investigation. Self-published, California (USA)

Stratakis G, Stamatelos A (2003) Thermogravimetric analysis of soot emitted by a modern diesel engine run on catalyst-doped fuel. Combustion and Flame 132:157-159, Pennsylvania (USA)

Sugawa O, Kawagoe K, Oka K, Ogahara I (1989) Burning behavior in a poorly ventilated compartment fire - ghosting fire. Fire Science \& Technology 9(2):5-14

Swab S (1985) Consideration of Depth of Char When Establishing Fire Burn Times. Fire and Arson Investigator Journal of the International Association of Arson Investigators 9:26-29, Crofton, MD

Tanaka T, Nakaya I, Yoshida M (1985) Full Scale Experiments for Determining the Burning Conditions to be Applied to Toxicity Tests. Fire Safety Science-Proceedings of the 1st International Symposium, New York, NY, pp 129-139

Taroni F, Bozza S, Aitken C (2005) Decision analysis in forensic science. J Forensic Sci 50(4):894-905

Taroni F, Aitken C, Garbolino P, Biedermann A (2006) Bayesian Networks and Probabilistic inference in Forensic Science (Statistics in Practice). Wiley, Chichester (UK)

Taroni F, Bozzo S, Aitken C, Garbolino P, Biedermann A (2010) Data Analysis in Forensic Science: A Bayesian Decision Perspective. Wiley, Chichester (UK)

Taylor R (1985) Carpet, Wood Floor and Concrete "Burn Patterns" Often Are Not From Flammable Liquids....Are a highly misunderstood aspect of fire investigation. Fire and Arson Investigator Journal of the International Association of Arson Investigators 9:32-35, Crofton, MD

Taylor R (1986) Flammable and Combustible Liquid Characteristics in Certain Types of Fires - Part 2. Fire and Arson Investigator Journal of the International Association of Arson Investigators 15:16-19, Crofton, MD

Theobald C (1968) The Critical Distance for Ignition From Some Items of Furniture. Fire research station, Fire Research Note No. 736

Thomas P (1981) Testing products and materials for their contribution to flashover in rooms. Fire and Materials 5(3):130-141

Thomas I, Bennets I (1999) Fires in Enclosures with Single Ventilation Openings Comparison of Long and Wide Enclosure, Fire Safety Science Proceedings of the Sixth International Symposium

Thomas P, Heslden J (1972) Fully Developed Fires in Single Compartments, A Co-operative Research Program of the Conseil International du Batimen (CIB Report No. 20). Fire Research Station Note No. 923

Tinsley A, Gorbett G (2013) Fire Investigation Origin Determination Survey. Fire and Arson Investigator Journal of the International Association of Arson Investigators 63:24-40

Utiskul Y (2007) Theoretical and Experimental Study on Fully-Developed Compartment Fires. National Institute of Standards and Technology, NIST GCR 07-907

Utiskul Y, Quintiere J (2005) Generalizations on Compartment fires from Smallscale experiments for low ventilation conditions. Paper presented th the 8th IAFSS Symposium, London (UK)

Vesely W, Goldberg F, Roberts N, Haasl D (2002) Fault Tree Handbook. Nuclear Regulatory Commission. NUREG-0492

Von Winterfeldt D, Edwards W (1986) Decision Analysis and Behavioral Research. Cambridge University Press, Cambridge (UK)

Walton W, Thomas P (2008) Estimating Temperatures in Compartment Fires. Section 3, Ch. 6, 4th edn. SFPE Handbook of Fire Protection Engineers, NFPA, MA

Wieczorek C, Vandsburger U, Floyd J (2004) An evaluation of the global equivalence ratio concept for compartment fires: data analysis methods. Journal of Fire Protection Engineering 14:9-31

Williamson R, Revenaugh A, Mowrer F (1991) Ignition Sources in Room Fire Tests Ansome Implications for Flame Spread Evaluation. Fire Safety Science - Proceedings of the 3rd International Symposium, Elsevier Applied Science, New York, pp 657-667 
Wolfe A, Mealy C, Gottuk D (2009) Fire Dynamics and Forensic Analysis of Limited Ventilation Compartment Fires Volume 1: Experimental. National Institute of Justice, Grant \# 2007-DN-BX-K240

Wood C, Simeoni A, Foley R (2012) Preliminary Results of the Effect of Carpet Pad Seams Compared to Ignitable Liquid Pours, Floor Fire Patterns in

Post-Flashover Fires, Paper presented at the International Symposium on Fire Investigations. Investigations Institute, Florida (USA)

Submit your manuscript to a SpringerOpen ${ }^{\circ}$ journal and benefit from:

- Convenient online submission

- Rigorous peer review

- Immediate publication on acceptance

- Open access: articles freely available online

- High visibility within the field

- Retaining the copyright to your article

Submit your next manuscript at $\gg$ springeropen.com 